\title{
Socially Complex Breeding Interactions in Humpback Whales Are Mediated Using a Complex Acoustic Repertoire
}

\author{
Dana A. Cusano ${ }^{1 * \dagger}$, David Paton ${ }^{2}$, Michael J. Noad ${ }^{1}$ and Rebecca A. Dunlop ${ }^{1}$ \\ ${ }^{1}$ Cetacean Ecology and Acoustics Laboratories, School of Veterinary Science, The University of Queensland, Gatton, QLD, \\ Australia, ${ }^{2}$ Blue Planet Marine, Canberra, ACT, Australia
}

\section{OPEN ACCESS}

Edited by:

Janet Mann

Georgetown University, United States

Reviewed by:

Vivienne Foroughirad,

Georgetown University, United States

Ellen Jacobs,

Georgetown University, United States, in collaboration with reviewer VF

Marc Lammers,

Hawaiian Islands Humpback Whale National Marine Sanctuary, United States

*Correspondence:

Dana A. Cusano

danacusano@gmail.com

tPresent address:

Dana A. Cusano,

JASCO Applied Sciences, Capalaba,

QLD, Australia

Specialty section:

This article was submitted to

Marine Megafauna,

a section of the journal

Frontiers in Marine Science

Received: 08 February 2021

Accepted: 07 October 2021

Published: 03 December 2021

Citation:

Cusano DA, Paton D, Noad M

and Dunlop RA (2021) Socially

Complex Breeding Interactions

in Humpback Whales Are Mediated

Using a Complex Acoustic Repertoire.

Front. Mar. Sci. 8:665186.

doi: 10.3389/fmars.2021.665186
Intraspecific conflict can be costly; therefore, many species engage in ritualized contests composed of several stages. Each stage is typically characterized by different levels of aggression, arousal, and physical conflict. During these different levels of "intensity," animals benefit from communicating potential information related to features such as resource holding potential, relative fighting ability, level of aggression, intent (i.e., fight or flight), and whether or not the competitor currently holds the resource (e.g., a receptive female). This information may be conveyed using both visual displays and a complex acoustic repertoire containing fixed (e.g., age, sex, and body size) and flexible information (e.g., motivation or arousal). Calls that contain fixed information are generally considered "discrete" or stereotyped, while calls that convey flexible information are more "graded," existing along an acoustic continuum. The use of displays and calls, and the potential information they convey, is likely dependent on factors like intensity level. The breeding system of humpback whales (Megaptera novaeangliae) involves intense male competition for access to a relatively limited number of breeding females (the resource). Here, we investigated the behavior and acoustic repertoire of competitive groups of humpback whales to determine if an increase in intensity level of the group was correlated with an increase in the complexity of the vocal repertoire. We categorized the behavior of humpback whales in competitive groups into three mutually exclusive stages from low to high intensity. While discrete calls were infrequent compared to graded calls overall, their use was highest in "low" and "moderate" intensity groups, which may indicate that this stage of contest is important for assessing the relative resource holding potential of competitors. In contrast, visual displays, call rates, and the use of graded call types, were highest during "high intensity" competitive groups. This suggests that flexible information may be more important in "high intensity" levels as males continue to assess the motivation and intent of competitors while actively engaged in costly conflict. We have shown that the relatively complex social call repertoire and visual displays of humpback whales in competitive groups likely functions to mediate frequently changing within-group relationships.

Keywords: competition, discrete calls, graded calls, intraspecific conflict, resource holding potential, social system 


\section{INTRODUCTION}

Intraspecific conflict arises when critical resources are limited, such as food, territory, or access to breeding opportunities (Campagna, 2009; Bradbury and Vehrencamp, 2011; Hardy and Briffa, 2013). Arguably the most common source of agonistic interaction involves the latter, particularly competition between males for access to reproductive females (Campagna, 2009). Conflict can be costly, requiring high energy expenditure and possibly injury or death (Campagna, 2009). In order to prevent serious injury, many species employ the strategy of "ritualized fighting," where competition escalates in successive stages that provide potential information on the contestants (Smith and Price, 1973; Maynard-Smith, 1974). This includes each individual's relative resource holding potential (RHP), which are the physiological and morphological traits (e.g., fitness and fighting ability) that primarily determine the outcome of a contest (Parker, 1974). Additional factors may also contribute to deciding the outcome of a conflict, including motivation, aggressiveness, and ownership status of the resource (Parker, 1974; Allen and Krofel, 2017). Individuals benefit from conveying this information continuously to facilitate decisions on whether to retreat or to engage. Males that produce honest signals indicative of strength and large body size, therefore, should persuade inferior opponents to avoid or disengage from combative situations they will likely lose, with fewer serious conflicts and injuries for both parties (Maynard-Smith and Harper, 2003). If competitors choose to proceed and aggression escalates, signaling behavior often reflects this escalation (Bradbury and Vehrencamp, 2011; Hof and Podos, 2013).

In an acoustic signaling system, this breadth of potential information requires a complex communicative repertoire, including calls that convey both fixed and flexible information. Acoustic cues related to fitness or fighting ability are typically correlated with fixed attributes which do not change over time or change slowly (Marler, 1961, 1977; Green and Marler, 1979). This includes features related to RHP, such as sex, body size, or age class. These calls tend to be highly stereotyped ("discrete") in that the call structure has little variability in acoustic features between- and within-contexts in order to reliably encode these traits. For example, the discrete "groans" of fallow deer (Dama dama) are displays produced during the breeding season to convey information on body size (Vannoni and McElligott, 2008; Charlton and Reby, 2011). As large body size in these animals is generally associated with higher rank, RHP, and mating success (McElligott et al., 2001), these acoustic features can be used by potential competitors to assess the odds of successfully winning an agonistic encounter (McElligott and Hayden, 1999). Red deer stags (Cervus elaphus), another species in which males defend harems, engage in "roaring contests" during the breeding season (Clutton-Brock and Albon, 1979; Reby et al., 2005). Males use the acoustic features of "roars" to remotely assess the fighting ability of their opponents. If neither male withdraws, the rate of roaring increases. Males also move closer together to signal RHP using visual displays. If males are evenly matched, or neither backs down, the interaction may then escalate to physical combat (Clutton-Brock and Albon, 1979).
Considering that factors other than RHP help to determine the outcome of a conflict, it may also be beneficial to convey information such as intent (i.e., willingness to fight, disengage, or not engage) or level of aggression during a contest (Morton, 1982; Enquist, 1985). This information is considered flexible, and is related to internal factors such as physiological or motivational state, as well as external factors such as social context (Marler, 1961, 1975, 1976; Morton, 1977; Hauser, 1996; Manser, 2010). Unlike discrete calls, those that contain flexible information tend to be variable, or "graded," both within and between calls. It is this gradation that provides listeners with information on the subtle variations in the signaler's internal attributes at the time of the call (Marler, 1961, 1976; Morton, 1977, 1982; Owings and Morton, 1998; Briefer, 2012). As escalation progresses beyond threats and displays, it may become increasingly more important to communicate flexible information (e.g., intent) rather than fixed information (e.g., body size or condition), especially considering that smaller animals with higher motivation are sometimes able to dominate larger opponents (Wagner, 1989; Kotiaho et al., 1999; Hofmann and Schildberger, 2001). For example, changes in the dominant frequency and temporal features of a graded call found in cricket frogs (Acris crepitans) provides accurate information regarding the intent of an individual, or how willing it is to progress in a conflict, independent of its body size. Males that attacked an opponent produced longer duration calls with more pulses per call than those that tolerated an opponent. Additionally, males that fled an opponent significantly lowered the dominant frequency of their call, while those that attacked lowered this frequency even further (Burmeister et al., 2002).

The frequency of intraspecific conflict and its intensity are partially dependent on the complexity of the social system (Campagna, 2009). Socially complex species that live in dense societies and have a polygamous mating system have more opportunities and motives to engage in conflict, particularly during the breeding season. Most baleen whales (i.e., the filterfeeding whales) have a relatively simple social system (Berta and Sumich, 1999; May-Collado et al., 2007), with little evidence of permanent groups, kin recognition, and long-term associations (but see Weinrich, 1991; Clapham, 1993; Ramp et al., 2010). There is also a tendency toward mating strategies that do not include overt aggressive male competition for mates (Boness et al., 2002). While some baleen species do engage in agonistic or competitive behaviors associated with breeding, the level and intensity of aggression is lower in species which engage primarily in sperm competition [e.g., North Atlantic right whales, Eubalaena glacialis (Kraus and Hatch, 2001; Parks, 2003; Parks and Tyack, 2005; Parks et al., 2007); southern right whales, Eubalaena australis (Clark, 1983, 1990; Payne and Dorsey, 1983); bowhead whales, Eubalaena mysticetus (Würsig et al., 1993; Rugh and Shelden, 2009)]. Humpback whales (Megaptera novaeangliae) do not utilize sperm competition and instead males have two main strategies; displaying using complex patterned songs (Payne and McVay, 1971), and more direct, physical competition for access to females (Brownell and Ralls, 1986; Clapham, 1996; Mesnick and Ralls, 2009). While song is well described, its function is not yet fully understood. Physical competition between males, however, is clear and results in 
the formation of large assemblages termed "competitive groups" (Tyack and Whitehead, 1983; Baker and Herman, 1984; Silber, 1986; Mattila et al., 1989; Clapham et al., 1992; Clapham, 1996; Pack et al., 1998; Darling and Bérubé, 2001; Herman et al., 2007; Félix and Novillo, 2015).

Competitive groups appear to function in intrasexual competition between males for access to a relatively limited number of breeding females (the resource) (Tyack and Whitehead, 1983). There is a definitive structure to groups, with multiple male escorts centered around a nuclear female (Tyack and Whitehead, 1983; Clapham et al., 1992; Brown and Corkeron, 1995). The escort that maintains the closest position to the female is the "principal," or "primary," escort. Primary escorts are challenged by other "secondary" escorts and will defend their close proximity to the female. Secondary escorts not only compete with the primary escort for this position, but also compete amongst themselves. In large and active groups, the composition and dynamic changes often, with principal escorts and secondary escorts changing positions and roles frequently (Tyack and Whitehead, 1983; Clapham et al., 1992). In addition, there are sometimes animals on the periphery of the group, typically smaller (i.e., juveniles or sub-adults), that appear to play a more observational role (Spitz et al., 2002). Competitive groups can vary in intensity, progressing from low to high levels of aggression and arousal (Baker and Herman, 1984). Usually, all males within the main group behave in a similar way, therefore intensity level can be classified at the group level. Low intensity (i.e., low aggression and arousal) groups are characterized by animals which have no direct physical contact and instead rely on displays and chasing behavior (Darling, 2001). Other "non-contact" agonistic display behaviors include blowing streams of bubbles, jaw clapping, and extending the throat pleats. Moderate intensity levels are indicated by more "intermediate" levels of aggression, with "head lunging" one of the most common behaviors observed (Baker and Herman, 1984). In contrast, higher intensity competitive groups tend to move more erratically and have elevated respiration rates (Tyack and Whitehead, 1983; Silber, 1986; Clapham et al., 1993). They also exhibit more aggressive behaviors, which can include "body thrashes," "tail lashes," collisions, injuries, and in one documented extreme case, death (Tyack, 1981; Tyack and Whitehead, 1983; Baker and Herman, 1984; Silber, 1986; Pack et al., 1998; Darling, 2001).

The dynamics of competitive groups likely depend on each competitor's relative RHP, based on attributes such as its size and position within the group, as well as levels of aggression and stamina. However, competitive groups are temporary and unstable, with new animals frequently splitting and joining (Tyack and Whitehead, 1983; Clapham et al., 1992). As each individual's relative RHP will change with changing group membership, this requires relationships to be quickly established and continuously re-established over the course of a conflict and throughout the breeding season. The number, diversity, and instability of relationships, and the frequently changing relative RHP of individuals in competitive groups would seemingly require a complex communication system. Humpbacks have the most variable, complex, and well-studied vocal repertoire of any of the large whales (Edds-Walton, 1997). Males produce stereotyped songs during the breeding season (Payne and McVay, 1971), and all humpback whales produce a large repertoire of social calls. These calls are produced by all age and sex classes (Winn et al., 1979; Zoidis et al., 2008; Indeck et al., 2021), and in all habitats [e.g., breeding grounds (Tyack and Whitehead, 1983; Silber, 1986), feeding grounds (Jurasz and Jurasz, 1979; D’Vincent et al., 1985; Thompson et al., 1986; Stimpert et al., 2007, 2011; Parks et al., 2014; Fournet et al., 2015), and on migration (Dunlop et al., 2007, 2008; Cusano et al., 2020)]. The number of calls within the repertoire is variable, depending on the population, habitat area, and behavioral context (Dunlop et al., 2007; Stimpert et al., 2008; Fournet et al., 2015; Rekdahl et al., 2017; Cusano et al., 2020). These social calls can be highly flexible in structure, ranging from low-frequency "grumbles" to highfrequency "chirps." Further, the acoustic repertoire of humpback calls includes both discrete and graded call types (Cusano et al., 2021), which may be related to the complexity of the social interaction (Cusano, 2021).

Here, we collected dedicated acoustic and behavioral data from competitive groups of humpback whales in order to test the hypothesis that their complex social call repertoire functions to mediate complex social interactions. We predicted that discrete and graded calls perform different functions during agonistic competitive interactions, and this will be reflected in differential use of these calls as intensity changes. Following trends evident in terrestrial species like deer, we hypothesized that discrete calls would be used more often in groups with lower levels of perceived group aggression (i.e., during agonistic displays) where it is more important to convey fixed information on RHP. In contrast, graded calls would increase with the perceived level of aggression (i.e., overt aggression) in order to convey flexible information regarding intent and motivation to escalate or continue conflict. Additionally, we hypothesized that call rates would increase linearly with group size and intensity, as increased call production is known to be correlated with high arousal in humpback whales (Cusano et al., 2020). The results from this study can ultimately increase our understanding of discrete and graded call use within an animal that engages heavily in male competition during the breeding season and provide a foundation for making comparisons between vocal behavior, mating strategies, and sociality in other baleen whales.

\section{MATERIALS AND METHODS}

Behavioral and acoustic data were collected on competitive groups of humpback whales on the breeding grounds in the Great Barrier Reef (Figure 1). Effort focused on the Whitsunday Island group which has high densities of humpback whales during the breeding season (Smith et al., 2012). Data collection was conducted in four consecutive years between July and September, 2016-2019. Data were collected from 6 to $7 \mathrm{~m}$ rigidhulled inflatable boats on days with winds less than 15 knots and a sea state less than Beaufort 4. Competitive groups were located opportunistically, and were defined as two or more adults centered around a nuclear animal (assumed to be female) 


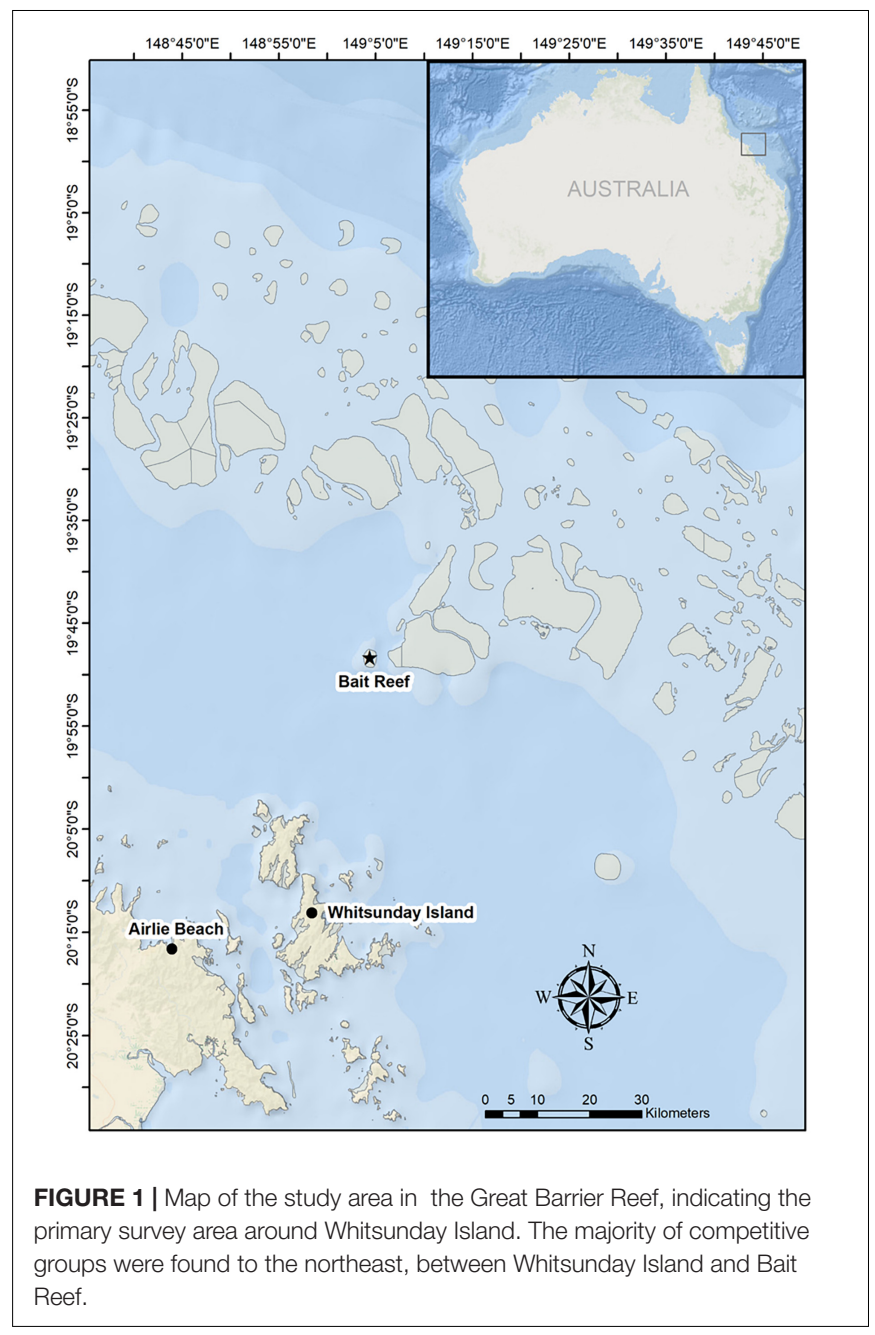

and demonstrating agonistic surface-active or chasing behavior (Tyack and Whitehead, 1983; Clapham et al., 1992). Due to the challenges of obtaining biopsy samples in competitive groups, no information was available on the sex of most individuals, so it was impossible to say with certainty whether the nuclear animal was always female. Although all male competitive groups have been observed, these are relatively uncommon (Clapham et al., 1992; Brown and Corkeron, 1995). They are thought to function in dominance sorting, which would only be useful if individuals encounter each other frequently (Clapham, 1993), unlikely in a population this size (2015 absolute abundance estimate 24,545; Noad et al., 2019). Therefore, all competitive groups in the present study likely contain at least one female.

\section{Behavioral Data}

After sighting a competitive group, a behavioral focal follow was initiated using continuous focal animal sampling methods (Altmann, 1974). Recorded data included the number of animals in the group, approximate group speed based on the vessel speed, and the frequency of occurrence of specified behaviors. These behaviors were selected based on previous research on humpback competitive groups in other areas (Tyack and Whitehead, 1983;
Baker and Herman, 1984; Silber, 1986; Mattila et al., 1989; Clapham et al., 1992; Clapham, 1996; Pack et al., 1998; Darling and Bérubé, 2001; Herman et al., 2007; Félix and Novillo, 2015) and formed the behavioral ethogram for the study (Table 1).

An intensity scale was established based on the estimated speed of the group, an estimate of the number of breaths per whale during each surfacing (given that animals performing high intensity behaviors tend to have elevated respiration rates, Helweg and Herman, 1994), and the presence and frequency of aggressive behaviors. The designation of an aggressive or highly aggressive behavior was primarily based on whether or not there was direct physical contact, or perceived attempted physical contact, between group members. For example, a "tail slap" is a behavior in which the fluke is raised out of the water and forcibly slapped against either the surface (aggressive) or another whale (highly aggressive) (Tyack, 1981; Tyack and Whitehead, 1983). Identification photographs were also taken of all animals in the group during the focal follow. Humpback whales may be individually identified using distinct markings on the tail (flukes) and the shape of the dorsal fin (Katona and Whitehead, 1981). Due to the size and continued rapid growth of the east Australian humpback whale population, the resighting of individuals is rare (Burns et al., 2014). Therefore, individuals could only be identified for the duration of the follow. Photos were used to corroborate the number of animals present, confirm the roles of individuals (e.g., the leading animal was presumed to be the nuclear female), and determine if individuals maintained consistent roles (e.g., displacement of the presumed primary or secondary escorts based on position to the nuclear female).

Each follow was assigned an intensity level by a trained observer using the behavioral ethogram. Intensity level was based on the behavior of the group as a whole. A new intensity level was assigned if the behavior of the group changed during the follow with no break in data collection. Three group intensity levels were determined from the behavioral focal follow data (Table 2). Level one ("low intensity") was characterized by the fastest swim speeds (>10 kts) and few course changes. It often appeared as if one animal was consistently leading (as identified using dorsal fin and fluke identification markings and shape), with the remaining animals following behind or chasing. Level two ("moderate intensity") was associated with slower speeds $(<10$ kts), more time spent at the surface, and a more erratic course (i.e., more course changes), and more surface-active behaviors (e.g., flipper slapping and tail slapping) compared with low intensity level groups. Many of these behaviors were identified as aggressive, but not highly aggressive, because of the lack of direct body contact (Tables 1, 2). Lastly, level three ("high intensity") groups were similar in speed and time spent at the surface to moderate intensity level groups, but characterized by a higher frequency of highly aggressive behaviors such as tail slashing, and chin or head slaps on other group members (Tables 1, 2). Animals during these follows would periodically surface with blood on their dorsal fins, indicative of this direct physical contact.

\section{Acoustic Data}

Acoustic recordings were collected using a Zoom H4n Pro Handy Recorder (Zoom North America, $44.1 \mathrm{kHz}$ sampling rate, 
TABLE 1 | Behavioral ethogram for humpback whale competitive groups.

\begin{tabular}{|c|c|}
\hline Behavior & Description \\
\hline Body slam ** & The collision of two or more whales. \\
\hline Breach ** & $\begin{array}{l}\text { Leap in which the entire, or part of, the whale body (up to the tail stock) exits the water. The whale twists in the air and } \\
\text { lands on its dorsal or lateral side. Includes half breaches and other variations. Considered highly aggressive in this } \\
\text { context as it was typically aimed at other individuals. }\end{array}$ \\
\hline Bubble streaming * & Blowing bubble streams underwater. \\
\hline Chin/Head Slap * or ** & $\begin{array}{l}\text { The head is raised out of the water and slapped against the water's surface (aggressive) or another whale (body } \\
\text { contact-highly aggressive) }\end{array}$ \\
\hline Open/Distended Pleats * & The distension of the ventral grooves or pleats to make the animal appear bigger in size. \\
\hline Head Lunge ** & $\begin{array}{l}\text { Energetic forward motion with a forward lunge of the head, with less than } 40 \% \text { of the body leaving the water with an } \\
\text { angle to the water }<45^{\circ} \text {. }\end{array}$ \\
\hline Jaw Clap * & Forceful opening and closing of the mouth. \\
\hline Pec Slap * or ** & $\begin{array}{l}\text { The left or right pectoral or both pectorals are raised out of the water and forcibly slapped against the water's surface } \\
\text { (aggressive) or another whale (body contact-highly aggressive). }\end{array}$ \\
\hline Roll & Surface or underwater roll in any direction or plane. Includes belly up. \\
\hline Peduncle Throw/Rear body thrash * or ** & $\begin{array}{l}\text { The throwing of the entire fluke and peduncle in a lateral motion out of the water (aggressive) or at/on another whale } \\
\text { (body contact-highly aggressive). No initial lifting from the water as in a peduncle or tail slap, just a single scything } \\
\text { motion. }\end{array}$ \\
\hline Tail Slap/Lobtail * or ** & $\begin{array}{l}\text { The fluke is raised out of the water and forcibly slapped against the water's surface (aggressive) or another whale (body } \\
\text { contact-highly aggressive) }\end{array}$ \\
\hline Tail Slash/Flick * or ** & $\begin{array}{l}\text { Movement of tail in a sideways motion through water (aggressive) or at/on another whale (body contact-highly } \\
\text { aggressive) }\end{array}$ \\
\hline Tonal Blow/Trumpet * & Blow accompanied by a loud vocalization, usually low frequency. \\
\hline Underwater blow * & A forceful, audible release of breath underwater \\
\hline
\end{tabular}

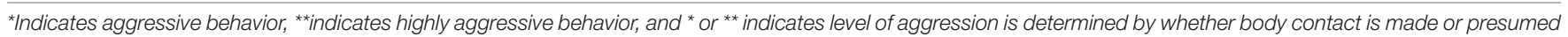
to be attempted.

TABLE 2 | Intensity scale developed for competitive groups based on the behaviors outlined in the ethogram and observations of speed and breathing rates.

\begin{tabular}{|c|c|c|}
\hline Intensity level & Est. avg. speed (kts) & Key behaviors \\
\hline 1 (Low) & $10+$ & $\begin{array}{l}\text { Fast travel in a steady direction, long down times, } \sim 3 \text { blows/surfacing; chasing behavior, often with } \\
\text { a consistent animal leading; limited presence of aggressive behaviors like head lunges, pec slaps, } \\
\text { tail slaps (1-2 displays per surfacing). }\end{array}$ \\
\hline 2 (Moderate) & $5-10$ & $\begin{array}{l}\text { Slower travel in no clear direction, with shorter down times and longer surface times, } \sim 4 \\
\text { blows/surfacing; increased presence of aggressive behaviors, but limited or no heightened } \\
\text { aggressive behaviors. }\end{array}$ \\
\hline 3 (High) & $<5$ & $\begin{array}{l}\text { Even slower travel, although with similar down times and surface times as } 2 \text {; increased presence of } \\
\text { aggressive behaviors (more than } 10 \text { displays per surfacing); addition of heightened aggressive } \\
\text { behaviors like direct body contact and breaches; evidence of blood on tubercles and dorsal fins. }\end{array}$ \\
\hline
\end{tabular}

16 bit) and an HTI-96-MIN hydrophone with built in +40 $\mathrm{dB}$ pre-amplifier dropped over the side of the boat (High-Tech, Inc.). The engine was shut down during recordings to minimize background noise. Although humpback whale calls are reported to have an estimated active space of up to $4 \mathrm{~km}$ in winddominated noise (Dunlop, 2018b), and up $2.5 \mathrm{~km}$ in vessel noise (Dunlop, 2018a), the acoustic environment in the study area was dominated by additional biotic noise (i.e., snapping shrimp, humpback whale song chorusing). Therefore, data were only collected when whales were within $400 \mathrm{~m}$ of the boat in order to ensure that all calls from the group were detected. Any whales within this distance were either involved in the competitive group or alone. As lone humpback whales rarely vocalize (Silber, 1986; personal observation), it is unlikely that calls were detected from animals outside the focal group. Due to the high speeds and often erratic behavior of competitive groups, the duration of acoustic recordings was limited to short periods (average duration 6 min $15 \mathrm{~s}$, range 1-10 recordings per follow).

Spectrograms of recordings were visually and aurally browsed in Raven Pro 1.5 (Center for Conservation Bioacoustics [CCB], 2014, RRID:SCR_016190) using a Hann window, Fast Fourier Transform size of 4,096 samples, and 90\% overlap. All humpback whale social calls were marked and extracted for further analysis. The nearly constant background song from singing males in the area meant that most calls detected from competitive groups had overlapping song units of varying amplitude. This precluded any analysis of acoustic features (e.g., frequency and bandwidth). The overlapping song also prevented any automated classification techniques like those used in previous social call analyses (Stimpert et al., 2011; Fournet et al., 2015; Rekdahl et al., 2017; Cusano et al., 2020, 2021; Indeck et al., 2021). Therefore, in order to determine call types, the results from a previous humpback 
social call analysis were used (Cusano et al., 2021) that applied fuzzy k-means (FKM) clustering to humpback calls from the same population (Ferraro and Giordani, 2015; Wadewitz et al., 2015; Fischer et al., 2017). Similar to other clustering methods, an FKM partitions data-points (individual calls) into clusters based on a set of user-defined features. In contrast to other clustering methods, however, fuzzy clustering assigns each datapoint a membership value to each of the clusters while allowing intermediate membership between clusters (Bezdek, 1981). Based on cluster membership values, a typicality coefficient can then be calculated to define a threshold above or below which a call type could be considered discrete or graded, respectively (Wadewitz et al., 2015; Fischer et al., 2017; Cusano et al., 2021).

The FKM was run on a dataset of calls collected from the same population of humpback whales during their southward migration from the breeding ground in 2010, 2011, 2015, and 2017 (see Dunlop et al., 2015, 2016, for detailed data collection methodology). Using the FKM, calls were partitioned into clusters based on a set of 25 acoustic features, including temporal (e.g., duration), frequency (e.g., peak and center frequency), and bandwidth measurements. The FKM identified six discrete and seven graded call types (Cusano et al., 2021). A further thirteen were considered intermediate call types as they had average typicality coefficients that fell between the thresholds for discrete and graded calls. Following the results of the analysis, six call types were determined to be discrete, five of which were detected in the current study: "paired croak," "chirp," "harmonic squeak," "thwop," and "whup" (previously called "wop," Dunlop et al., 2007). In addition, individual song units are sometimes used as social calls in this population (Dunlop et al., 2007, 2008; Rekdahl et al., 2013). Although song units may have subtle variations in acoustic structure (Hafner et al., 1979), most males within a population follow the same song pattern at any given time, creating highly stereotyped songs (Winn and Winn, 1978; Payne et al., 1983; Payne and Payne, 1985; Garland et al., 2015; Allen et al., 2019). Song units were thus classified as discrete sounds in the present study. Calls detected from competitive groups that visually and aurally matched these discrete call types were assigned as that call. Calls that did not visually or aurally match one of the easily distinguishable discrete call types or that matched a graded or intermediate call type from the FKM were assigned as graded. Spectrograms of the discrete call types and an exemplar graded call are in Figures 2, 3. Sound clips can be found in Supplementary Material.

Graded call types often fall along an acoustic continuum (Marler, 1961, 1976; Marler et al., 1992), rendering them difficult to classify based on visual or aural characteristics alone. However, three measurements could be obtained directly from the spectrograms and were thus not influenced by background song: minimum frequency, maximum frequency, and call duration. To determine whether there were differences in the use of graded sounds at different intensity levels, a cluster analysis was run to objectively group graded sounds into broad call classes. Analyses were run using the $\mathrm{R}$ programming language ( $\mathrm{R}$ Core Team, 2020; RRID:SR_003005) with the partitioning around medoids (PAM) method in the package cluster (Maechler et al., 2019). This method is considered to be more robust than traditional $\mathrm{k}$-means clustering, representing cluster centers as medoids that are less sensitive to outliers than means. The pairwise distances between all of the data points were computed to obtain a matrix of the sum of dissimilarities using the Gower coefficient (Gower, 1971; Maechler et al., 2019). The resulting dissimilarity matrix was used to run the cluster analysis. Using the silhouette method (Kaufman and Rousseeuw, 2009), the recommended number of clusters was determined to be either two or five. The twocluster solution resulted in one cluster with a low silhouette width, indicating poor data structure (Kaufman and Rousseeuw, 2009), so the five-cluster solution was chosen. This resulted in five graded call classes: (1) low frequency, moderate duration; (2) mid-frequency, long duration; (3) broadband (i.e., spans a broad frequency range), very long duration; (4) high-frequency, short duration; and (5) very high-frequency, short duration.

\section{Statistical Analysis}

Call rates, the proportion of discrete and graded calls used, and the proportion of specific call types/classes used were modeled as a function of group intensity level to assess the differences in the communicative behavior within groups. Separate models were run for call rates and call proportions. Call rates were first standardized for varying group sizes by dividing the number of calls by the total number of animals. Then, rates were compared using generalized linear mixed models (GLMMs) with a negative binomial error distribution to model a quadratic relationship between the variance and mean (Brooks et al., 2017b). This allows for small counts (here, low call rates) to have similar weights to high counts (high call rates; Ver Hoef and Boveng, 2007). Models were run in $\mathrm{R}$ using the package $\operatorname{glmm} T M B$ (Brooks et al., 2017a). A log offset was applied to the fixed effect of "time" to provide rates (calls per time of deployment) rather than counts (number of calls). The number of animals in the group and group ID were included as random effects.

Next, a GLMM with a binomial error distribution for proportions was used to compare the use of discrete and graded calls between the intensity levels. The internally calculated proportion of discrete versus graded calls was the response variable, with the number of animals in the group and group ID added as random effects. Binomial GLMMs were run using the package lme4 (Bates et al., 2015). Additionally, separate models were run for each of the six discrete call types and the five graded call classes to investigate differences between group intensity levels. However, due to the low effect size for group ID for some call types/classes, no random effects could be included, and general linear models (GLMs) were used for the individual call type/class models. Post hoc analyses for all models were run using the emmeans package (Lenth, 2021) with the "mvt" method for exact Dunnett style contrasts between intensity levels.

\section{RESULTS}

A total of 43 competitive groups were observed and recorded in $2016(n=5), 2017(n=12), 2018(n=12)$, and $2019(n=14)$ with $20 \mathrm{~h}$ and $38 \mathrm{~min}$ of acoustic and behavioral data (Supplementary 


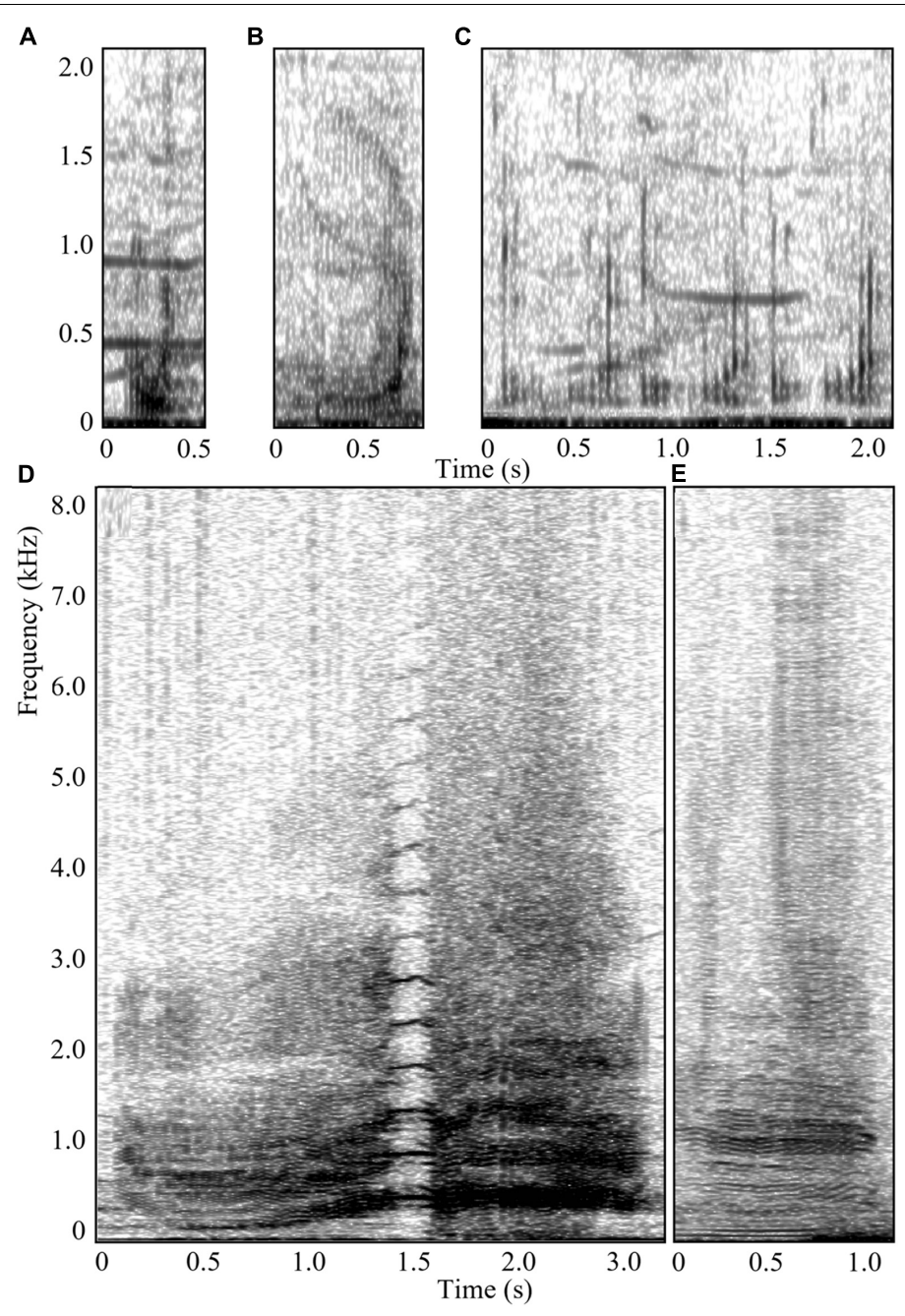

FIGURE 2 | Spectrograms (Hann window, Fast Fourier Transform 4096 samples, overlap 90\%) of the relatively low frequency call types detected in competitive groups during this study: (A) "thwop," (B) "whup," (C) a series of "paired croaks," (D) a graded call, and (E) a low frequency "song unit social call." Sound clips can be found in Supplementary Material.

Material). In order to maintain a workable distance of $<400 \mathrm{~m}$ (see section "Materials and Methods"), observations were broken up into 198 recordings from 59 focal follows. A large proportion of sightings of competitive groups (>75\%) were to the northeast of the major island groups, particularly between Whitsunday Island and Bait Reef (Figure 1). As per previous studies, the number of whales in competitive groups was highly variable (average $5.8 \pm 2.4 \mathrm{SD}$, range $3-16$ ).

\section{Intensity Level}

Low intensity groups were encountered during 23 focal follows (39\% of focal follows) for a total acoustic recording time of 05:18:57 from 67 recordings. The average group size was 5.7 animals (range 3-9). Moderate intensity groups were the most commonly observed, with a total of 29 focal follows (49\% of focal follows) and 11:59:50 total recording time from 108 recordings. The average group size for moderate intensity groups was 5.4 (range 3-11). Lastly, high intensity groups were the least common, encountered during 7 focal follows (12\% of focal follows) for a total recording time of 03:19:16 from 23 recordings. The average group size for level three was 8.9 animals (range 316). Intensity level was not correlated with the number of animals in the group (Fisher's exact test $p=0.3304$ ).

\section{Acoustic Behavior}

A total of 6,414 calls were detected over the study period: 971 during low intensity follows, 4,033 during moderate intensity follows, and 1,410 during high intensity follows. As expected, call rates (per whale per hour) increased with intensity level. Groups that were classified as being within the lowest intensity level had the lowest call rate (GLMM estimate $4.49 \pm 1.3 \mathrm{SE}$ calls/whale/h) compared to moderate $(12.5 \pm 3.0$ calls/whale/h), and high intensity groups $(18.2 \pm 6.8$ calls/whale/h). Though there was an increase in call rate per whale between moderate and high intensity level groups, these results were not significantly different, possibly due to differences in sample size (GLMM odds 


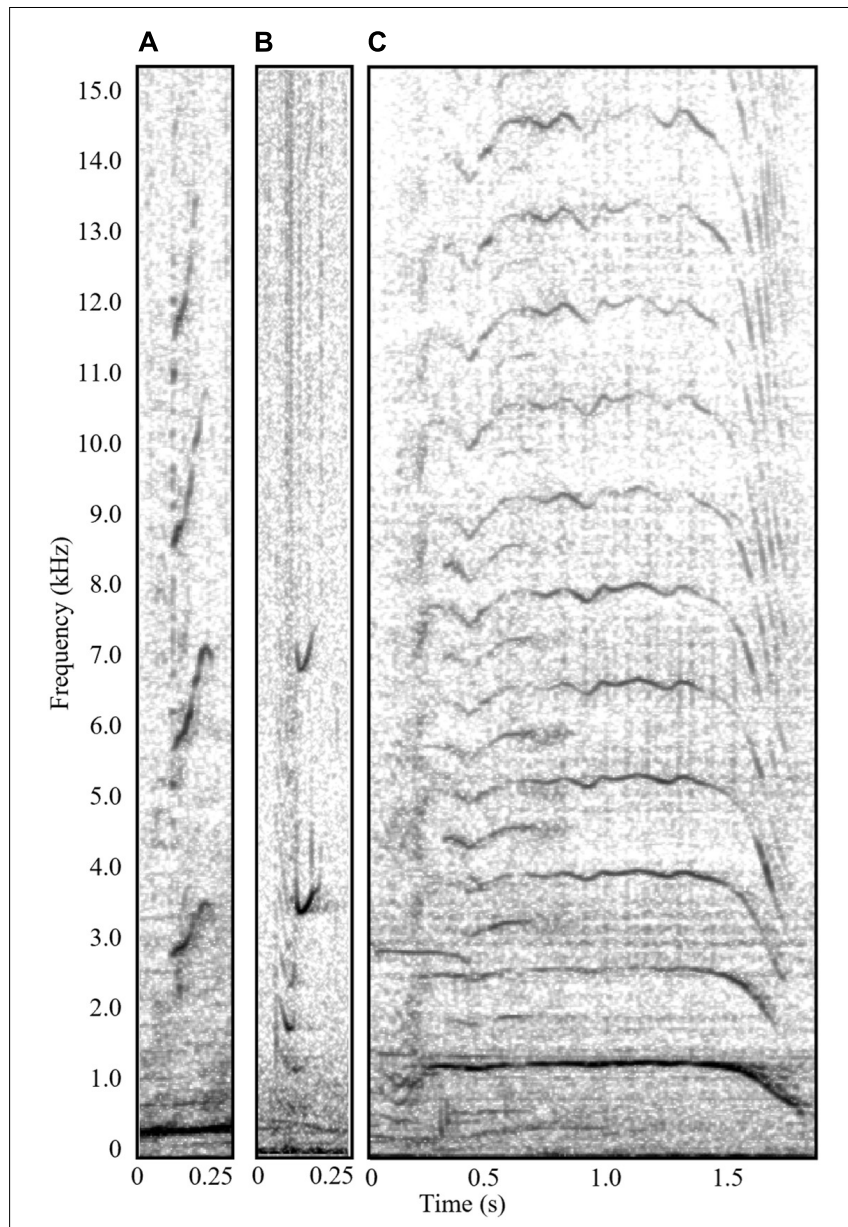

FIGURE 3 | Spectrograms (Hann window, Fast Fourier Transform 4096 samples, overlap 90\%) of the relatively high frequency call types detected in competitive groups during this study: (A) "harmonic squeak," (B) "chirp," and (C) a high frequency "song unit social call." Sound clips can be found in Supplementary Material.

ratio $0.69 \pm 0.24, \mathrm{t}$ ratio $=-1.08, p=0.5207)$. The significant difference between low and moderate intensity levels (odds ratio $0.36 \pm 0.10, \mathrm{t}$ ratio $=-3.62, p=0.0019)$, and low and high intensity levels (GLMM odds ratio $0.25 \pm 0.11$, $\mathrm{t}$ ratio $=-3.26$, $p=0.0051$ ) suggests there was a significant increase in the need for individuals to communicate in moderate and high intensity levels.

Of the total calls analyzed, 2,064 were classified as discrete calls (i.e., one of the five pre-defined call types) and 4,350 as graded calls (i.e., calls that did not fit into a discrete call type or were identified as graded or intermediate from the FKM). Vocalizing whales within all groups tended to use more graded calls than discrete calls regardless of intensity level (Figure 4 and Table 3 ). However, when comparing the use of discrete and graded calls between intensity levels, the probability of detecting graded calls was lower in low (GLMM average probability $0.71 \pm 0.07 \mathrm{SE}$ ) and moderate intensity levels $(0.82 \pm 0.05)$ compared with the high intensity level $(0.91 \pm 0.03$, Figure 4 and Table 3$)$. The results of the GLMM indicated this difference was significant

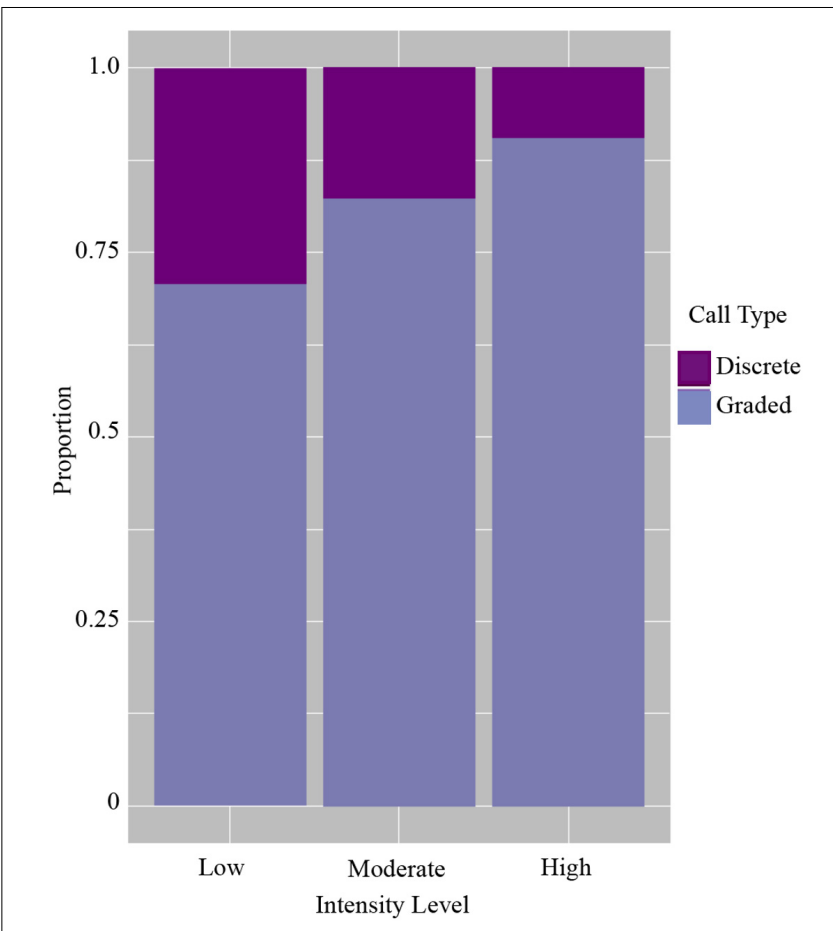

FIGURE 4 | Probability of detecting discrete and graded call types in the three intensity levels.

between all groups (Table 3). The highest probability of detecting graded calls was thus from groups in the highest intensity level, while the highest probability of detecting discrete calls was from groups in the lowest intensity level (Figure 4). This indicates that low intensity groups, where non-contact threats and displays are more common than overt contact aggression, may benefit more from communicating fixed information (e.g., body size) than moderate and high intensity groups. Additionally, these results suggest that graded calls are used more in escalated contests where contact aggression between whales is common, and these groups may benefit more from communicating flexible information (e.g., motivation and arousal).

When comparing the use of the six discrete call types, the GLM showed that groups that were low in intensity had a significantly higher probability of using certain discrete calls compared with moderate and high intensity levels (Figure 5 and Table 4). This included paired croaks (GLM average probability $0.21 \pm 0.03$ $\mathrm{SE}$ ), which are low-frequency, discrete calls produced in sequence and are only detected in groups containing one or more escorts (Cusano et al., 2020). Additionally, this call type is associated with an increase in arousal and social complexity, although the exact function is unknown (Cusano et al., 2020; Cusano, 2021). Whups and thwops, two additional low-frequency, discrete calls, also had a higher probability of detection in low intensity groups $(0.64 \pm 0.03$ and $0.03 \pm 0.01)$ compared with the other intensity levels (Figure 5 and Table 4), although the difference in the use of thwops between low and moderate intensity groups was not statistically significant. 
TABLE 3 | Results from the generalized linear mixed models with the probability of detecting discrete and graded calls in each intensity level in the first three columns, and the odds ratios in the last three columns.

\begin{tabular}{|c|c|c|c|c|c|c|}
\hline Call type & $\begin{array}{c}\text { Low } \\
\text { (prob. } \pm \text { SE) }\end{array}$ & $\begin{array}{l}\text { Moderate } \\
\text { (prob. } \pm \text { SE) }\end{array}$ & $\begin{array}{c}\text { High } \\
\text { (prob. } \pm \text { SE) }\end{array}$ & $\begin{array}{c}\text { Low-mod } \\
\text { (odds } \pm \text { SE) }\end{array}$ & $\begin{array}{l}\text { Low-high } \\
\text { (odds } \pm \text { SE) }\end{array}$ & $\begin{array}{l}\text { Mod-high } \\
\text { (odds } \pm \text { SE) }\end{array}$ \\
\hline Discrete & $0.29 \pm 0.08$ & $0.18 \pm 0.05$ & $0.09 \pm 0.03$ & $1.92 \pm 0.44$ & $3.94 \pm 1.16$ & $2.06 \pm 0.38$ \\
\hline Graded & $0.71 \pm 0.07$ & $0.82 \pm 0.05$ & $0.91 \pm 0.03$ & $\begin{array}{c}z \text { ratio }=2.85 \\
p=0.0111^{\star}\end{array}$ & $\begin{array}{l}\text { z ratio }=4.69 \\
p<0.0001^{\star \star}\end{array}$ & $\begin{array}{l}z \text { ratio }=3.94 \\
p=0.0003^{\star *}\end{array}$ \\
\hline
\end{tabular}

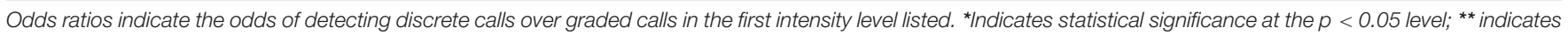
statistical significance at the $p<0.001$ level.

The GLM showed that moderate intensity groups modified their acoustic repertoire to include a larger proportion of "chirps" (GLM average probability $0.18 \pm 0.01 \mathrm{SE}$ ) compared to the other intensity levels, and "harmonic squeaks" (0.07 \pm 0.01$)$ compared to high intensity level groups (Figure 5 and Table 4). In addition, there was a greater probability of detecting song unit social calls in moderate intensity groups $(0.50 \pm 0.01)$ compared to low intensity level groups. The probability of detecting song unit social calls was increased further in high intensity groups $(0.78 \pm 0.02)$ (Figure 5 and Table 4). However, in contrast to low and moderate intensity levels, the song unit social calls primarily used in high intensity groups were low frequency, long duration units (Figures 2E, 3C).

Lastly, the use of the five graded call classes differed between the three intensity levels in several ways. All three intensity levels had the highest probability of using low-frequency, moderate duration graded calls (Figure 6 and Table 5). The most pronounced differences were in the use of certain graded call classes in the moderate intensity groups. There was a significantly higher probability of detecting broadband, very long-duration calls (Cluster 3) in moderate intensity groups (GLM average probability $0.16 \pm 0.01 \mathrm{SE})$ compared to low $(0.09 \pm 0.01)$ and high intensity groups $(0.05 \pm 0.01)$. In addition, high-frequency, short duration calls (Cluster 4 ) had the highest probability of detection in moderate intensity groups $(0.14 \pm 0.01)$, and this was significantly higher than low intensity groups $(0.09 \pm 0.01)$. The very-high frequency, short duration graded calls (Cluster 5) also had a higher probability of detection in moderate intensity groups $(0.05 \pm 0.004)$, which was significant compared to high intensity groups (0.02 \pm 0.01$)$ (Figure 6 and Table 5).

\section{DISCUSSION}

In terrestrial animals, intraspecific conflict often progresses from low-intensity threats and displays to escalated conflicts. As the conflict escalates, animals are provided with an opportunity to constantly reassess their opponents and avoid conflicts they are unlikely to win (Zahavi, 1982). This can be carried out using acoustic signals, which may convey aspects of the conflict such as the local strategy used by an opponent, their relative fighting ability, and properties of the resource (e.g., the breeding female) (Enquist, 1985). Here, we have shown that humpback whales appear to behave in a similar way during competitive behavior. As the intensity level of these competitive interactions increased, from low-level non-contact displays to high-level overt

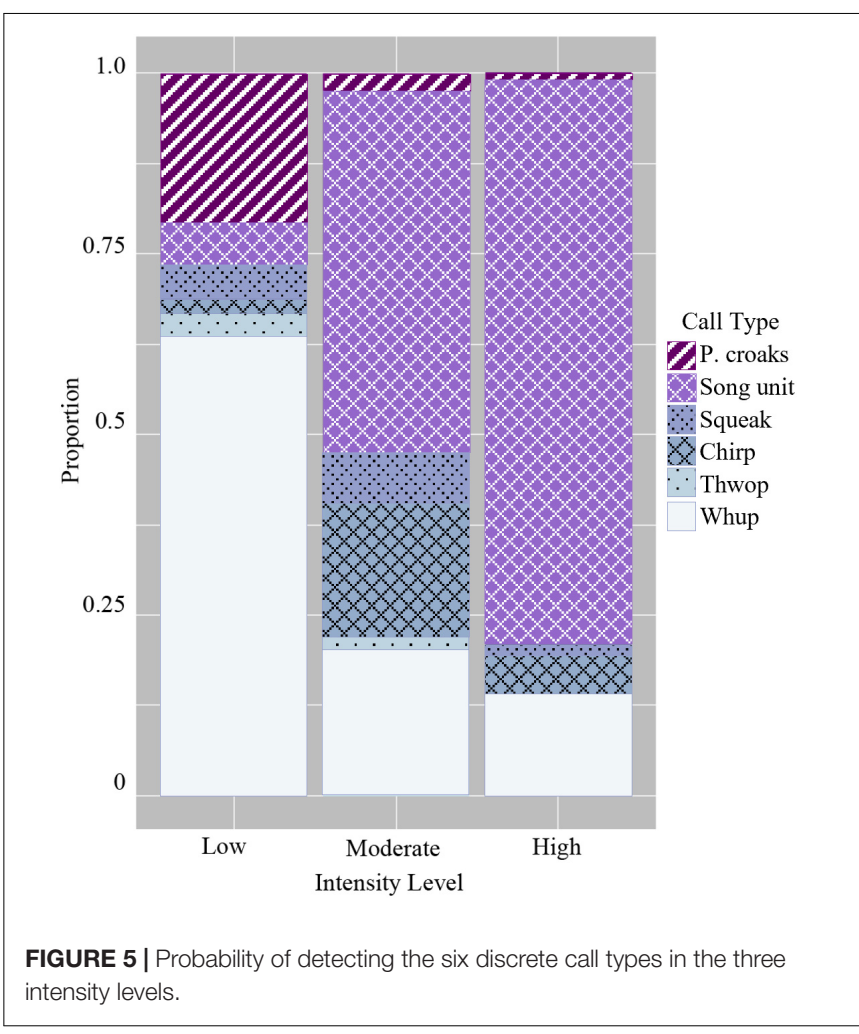

aggression, the calling behavior of these whales also changed. Low intensity groups were more likely to use discrete calls, and this probability decreased with intensity. In other species, discrete call types typically contain fixed information related to features like body size which may be important information to convey to opponents, particularly at the start of a conflict in an attempt to avoid escalation (Maynard-Smith and Harper, 2003). In contrast, higher intensity groups used more aggressive behaviors, had significantly higher call rates per animal, and used more graded calls within their repertoire. Therefore, for these whales, graded calls may provide more information on the intent of the caller, or their willingness to engage or continue to conflict. While no conclusion can be made about the intent of the caller, these results show that in humpback whales, the use of graded and discrete calls, as well as call rates, are clearly correlated with the level of intensity. These findings demonstrate possible similarities in mating strategies between a marine mammal and terrestrial species (particularly ungulates, Clapham, 1996), and 
TABLE 4 | Results of the generalized linear models, with the model calculated probability of each call type in each intensity level in the first three columns and the odds ratios in the last three columns.

\begin{tabular}{|c|c|c|c|c|c|c|}
\hline Discrete call type & $\begin{array}{c}\text { Low } \\
\text { (prob. } \pm \text { SE) }\end{array}$ & $\begin{array}{l}\text { Moderate } \\
\text { (prob. } \pm \text { SE) }\end{array}$ & $\begin{array}{c}\text { High } \\
\text { (prob. } \pm \text { SE) }\end{array}$ & $\begin{array}{l}\text { Low-mod } \\
\text { (odds } \pm \text { SE) }\end{array}$ & $\begin{array}{c}\text { Low-high } \\
\text { (odds } \pm \text { SE) }\end{array}$ & $\begin{array}{c}\text { Mod-high } \\
\text { (odds } \pm \text { SE) }\end{array}$ \\
\hline \multirow[t]{3}{*}{ Chirp } & $0.02 \pm 0.01$ & $0.18 \pm 0.01$ & $0.06 \pm 0.01$ & $0.09 \pm 0.04$ & $0.36 \pm 0.18$ & $4.04 \pm 0.80$ \\
\hline & & & & $\mathrm{z}$ ratio $=-5.27$ & $z$ ratio $=-2.08$ & $z$ ratio $=7.02$ \\
\hline & & & & $p<0.0001^{\star \star}$ & $p=0.0857$ & $p<0.0001^{\star \star}$ \\
\hline \multirow[t]{3}{*}{ Harmonic squeak } & $0.05 \pm 0.01$ & $0.07 \pm 0.01$ & $0.02 \pm 0.01$ & $0.70 \pm 0.21$ & $3.14 \pm 1.34$ & $4.49 \pm 1.52$ \\
\hline & & & & $z$ ratio $=-1.18$ & $z$ ratio $=2.67$ & $z$ ratio $=4.45$ \\
\hline & & & & $p=0.4579$ & $p=0.0196^{\star}$ & $p<0.0001^{\star \star}$ \\
\hline \multirow[t]{3}{*}{ Paired croaks } & $0.21 \pm 0.03$ & $0.02 \pm 0.004$ & $0.01 \pm 0.004$ & $10.64 \pm 2.60$ & $25.14 \pm 11.03$ & $2.36 \pm 1.07$ \\
\hline & & & & $z$ ratio $=9.69$ & $z$ ratio $=7.35$ & $z$ ratio $=1.90$ \\
\hline & & & & $p<0.0001^{\star \star}$ & $p<0.0001^{\star \star}$ & $p=0.1306$ \\
\hline \multirow[t]{3}{*}{ Song unit } & $0.06 \pm 0.01$ & $0.50 \pm 0.01$ & $0.78 \pm 0.02$ & $0.06 \pm 0.02$ & $0.02 \pm 0.005$ & $0.28 \pm 0.03$ \\
\hline & & & & $z$ ratio $=-10.11$ & $z$ ratio $=-14.02$ & $z$ ratio $=-10.98$ \\
\hline & & & & $p<0.0001^{\star \star}$ & $p<0.0001^{\star \star}$ & $p<0.0001^{\star \star}$ \\
\hline \multirow[t]{3}{*}{ Thwop } & $0.03 \pm 0.01$ & $0.02 \pm 0.004$ & $0.002 \pm 0.002$ & $1.78 \pm 0.75$ & $19.20 \pm 20.42$ & $10.78 \pm 11.04$ \\
\hline & & & & $z$ ratio $=1.38$ & $z$ ratio $=2.28$ & $z$ ratio $=2.32$ \\
\hline & & & & $p=0.3333$ & $p=0.0136^{\star}$ & $p=0.0471^{\star}$ \\
\hline \multirow[t]{3}{*}{ Whup } & $0.64 \pm 0.03$ & $0.20 \pm 0.01$ & $0.14 \pm 0.01$ & $6.91 \pm 1.03$ & $10.82 \pm 1.91$ & $1.57 \pm 0.22$ \\
\hline & & & & $z$ ratio $=12.98$ & $z$ ratio $=13.47$ & $z$ ratio $=3.24$ \\
\hline & & & & $p<0.0001^{\star \star}$ & $p<0.0001^{\star \star}$ & $p=0.0034^{*}$ \\
\hline
\end{tabular}

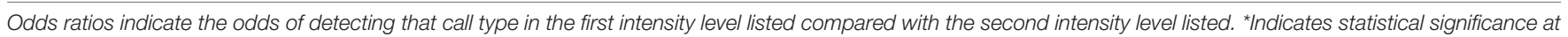
the $p<0.05$ level; ** indicates statistical significance at the $p<0.001$ level.

provide a basis for investigating what information content is actively conveyed in these contexts.

In this study, low intensity competitive groups were described as exhibiting little surface activity, and few overtly aggressive behaviors. Coupled with the low call rates and higher relative use of discrete calls (29\% probability of detection), we propose that communication during low intensity competitive groups potentially functions as a way for males to assess each other remotely without resorting to physical contact. This is further supported by the relatively fast speeds of these groups, which would make visual displays less functional since they require individuals to be in closer proximity (Silber, 1986). There is ample evidence in terrestrial species to suggest that discrete calls function to convey information to potential competitors, which could include resource holding potential (RHP), sex, age class, and body size (Reby and McComb, 2003b). For example, the discrete roars of red deer during the breeding season contain information regarding the age and weight of the sender (CluttonBrock and Albon, 1979; Reby and McComb, 2003a; Reby et al., 2005). These roars are relatively long in duration and are often produced in series. Roars are produced during the early stages of conflict, before escalation to physical fighting (Clutton-Brock and Albon, 1979). Here, whales within low intensity groups tended to use long duration, relatively low-frequency discrete call types such as paired croaks, which are always produced in a series to create relatively long duration sequences (Cusano et al., 2020). Further, this call type was used primarily in these lower intensity groups. Thus, it is possible that paired croaks function in a similar way to the roars of red deer, allowing individuals to gain valuable information on opponents in the early stages of intraspecific agonistic conflict.
Moderate and high intensity groups were considerably slower than intensity level one groups, and displayed more surfaceactive behavior. This included an increased number of aggressive behaviors like tail slashes and breaches (Tables 1, 2). In high intensity groups, there was evidence of direct body contact including open wounds and blood. There was also a linear increase in call rate from low intensity level groups. Here, we propose that whales are progressing to using more conspicuous displays, both visual and acoustic. In both moderate and high intensity groups, there was also a larger proportion of graded calls, signals that are potentially more indicative of motivation or intent (Morton, 1982; Enquist, 1985). As suggested by Silber (1986), these vocalizations may be used in conjunction with visual threats to convey aggression level more effectively than using only one signal modality (Smith, 1977). This is also seen in some seals and sea lions during agonistic interactions, where graded calls that convey level of threat and/or intensity are associated with visual displays (Insley et al., 2003).

There were significant differences in the use of higherfrequency calls between intensity levels, both in terms of discrete call types and graded call classes. This included discrete "chirps" and "harmonic squeaks," as well as high- and very high-frequency graded calls. In terrestrial species, calls that are high in frequency, harmonic, tonal, and have a simple pattern of frequency modulation have been associated with fear or appeasement contexts (Morton, 1977; August and Anderson, 1987; Briefer, 2012), or with distress (Lingle et al., 2012; Briefer, 2018). In distress situations, these sounds are thought to attract the attention or even alter the arousal level of conspecifics. As such, it could be expected that these relatively high frequency calls would have a higher probability of use in the highest 


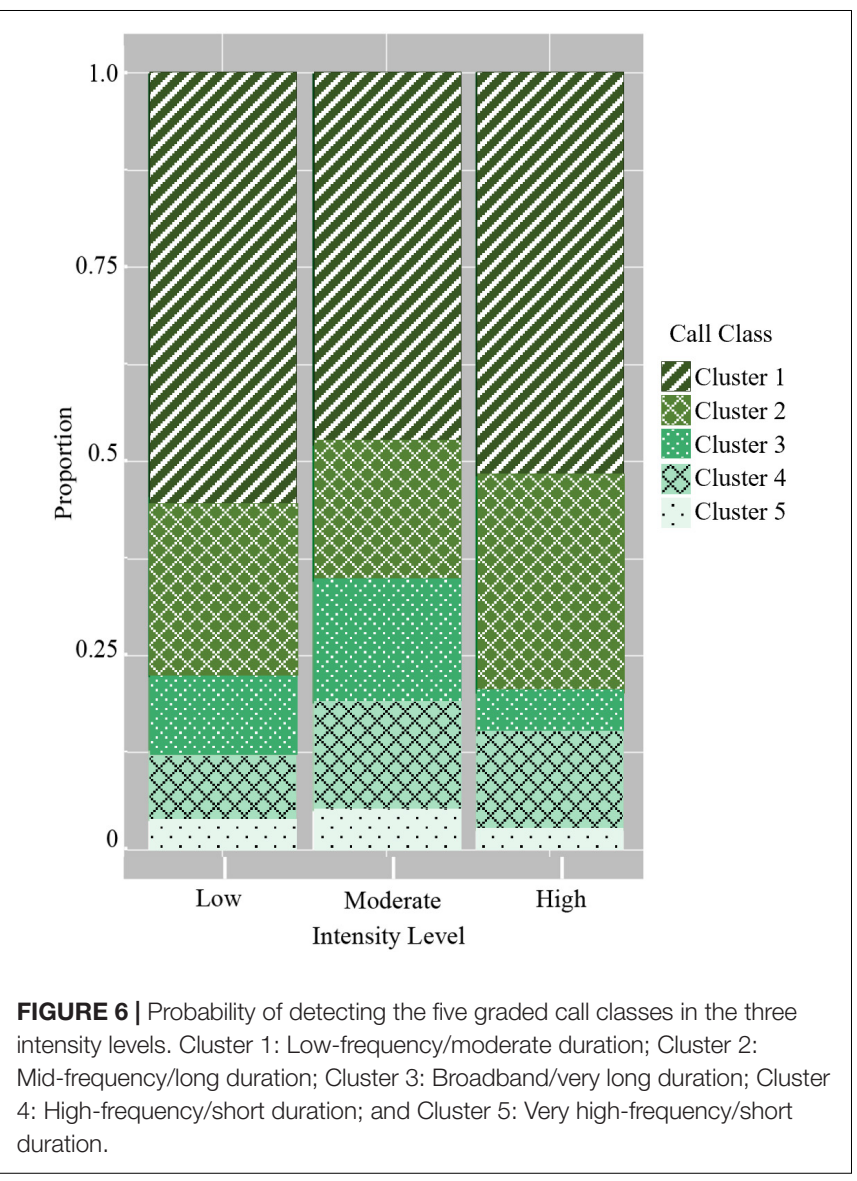

intensity competitive groups. Somewhat surprisingly, relatively high-frequency calls had a higher probability of detection in moderate intensity level groups. Of the high-frequency graded calls, and discrete "chirps" and "harmonic squeaks" produced in moderate intensity groups, roughly half occurred during focal follows with splits and joins. Previous research has shown that humpback whales use high-frequency calls often during the splitting and joining of group members, where changing hierarchies may occur (Dunlop et al., 2008; Cusano, 2021). Further research will be needed to determine if there is in fact a correlation between the stability of competitive groups and the use of relatively high frequency calls. However, combined with the results from previous studies, the results presented here provide preliminary evidence that high frequency calls may be particularly important during changing group dynamics, where information on intent and/or willingness to engage or disengage from competition could be beneficial to prevent further conflict.

Whales in aggressive, high-intensity groups emitted fewer discrete calls but interestingly the proportional use of song unit social calls increased. Song unit social calls are detected most often in lone males and groups of multiple animals, and are likely only used by males (Dunlop et al., 2008; Rekdahl et al., 2013). Song itself is a reproductive display, although its primary function has not been established (Tyack, 1981; Darling and Bérubé, 2001; Herman, 2017; Murray et al., 2018). It has been proposed to possibly function in female attraction, whether to an individual or to an area, and/or by facilitating male-male interactions (Herman, 2017). In either case, information contained in the song is likely available to both sexes (Murray et al., 2018) and could be used by eavesdroppers as well as intended recipients (Dunlop and Noad, 2016). The greatly increased use of song units as unpatterned social calls in the current study, particularly in more aggressive groups suggests that, at least as social calls, they are likely aimed at other males rather than females. The fact that song units have a lower source level when used in social contexts than when produced in song (Dunlop et al., 2013), and are produced at higher rates when males join groups of multiple adults, provides

TABLE $\mathbf{5}$ | Results of the generalized linear models for graded call classes, with the model calculated probability of each call class in each intensity level in the first three columns and the odds ratios in the last three columns.

\begin{tabular}{|c|c|c|c|c|c|c|}
\hline Graded call class & $\begin{array}{c}\text { Low } \\
\text { (prob. } \pm \text { SE) }\end{array}$ & $\begin{array}{l}\text { Moderate } \\
\text { (prob. } \pm \text { SE) }\end{array}$ & $\begin{array}{c}\text { High } \\
\text { (prob. } \pm \text { SE) }\end{array}$ & $\begin{array}{l}\text { Low-mod } \\
\text { (odds } \pm \text { SE) }\end{array}$ & $\begin{array}{l}\text { Low-high } \\
\text { (odds } \pm \text { SE) }\end{array}$ & $\begin{array}{l}\text { Mod-high } \\
\text { (odds } \pm \text { SE) }\end{array}$ \\
\hline \multirow{2}{*}{$\begin{array}{l}\text { Low- } \\
\text { frequency/moderate } \\
\text { duration }\end{array}$} & \multirow{2}{*}{$0.55 \pm 0.02$} & \multirow{2}{*}{$0.48 \pm 0.01$} & \multirow{2}{*}{$0.52 \pm 0.02$} & $1.30 \pm 0.11$ & $1.12 \pm 0.11$ & $0.86 \pm 0.07$ \\
\hline & & & & $p=0.0045^{\star}$ & $p=0.5327$ & $p=0.1184$ \\
\hline \multirow{2}{*}{$\begin{array}{l}\text { Mid-frequency/long } \\
\text { duration }\end{array}$} & \multirow[t]{2}{*}{$0.23 \pm 0.02$} & \multirow[t]{2}{*}{$0.18 \pm 0.01$} & \multirow[t]{2}{*}{$0.28 \pm 0.02$} & $1.43 \pm 0.14$ & $0.78 \pm 0.09$ & $0.55 \pm 0.05$ \\
\hline & & & & $z$ ratio $=3.52$ & $z$ ratio $=-2.13$ & $z$ ratio $=-6.58$ \\
\hline \multirow{3}{*}{$\begin{array}{l}\text { Broadband/very } \\
\text { long duration }\end{array}$} & \multirow{3}{*}{$0.09 \pm 0.01$} & \multirow{3}{*}{$0.16 \pm 0.01$} & \multirow{3}{*}{$0.05 \pm 0.01$} & $0.56 \pm 0.08$ & $1.99 \pm 0.41$ & $3.56 \pm 0.60$ \\
\hline & & & & $z$ ratio $=-4.23$ & $z$ ratio $=3.36$ & $z$ ratio $=7.54$ \\
\hline & & & & $p=0.0001^{\star \star}$ & $p=0.0022^{*}$ & $p<0.0001^{\star \star}$ \\
\hline \multirow{3}{*}{$\begin{array}{l}\text { High- } \\
\text { frequency/short } \\
\text { duration }\end{array}$} & \multirow[t]{3}{*}{$0.09 \pm 0.01$} & \multirow[t]{3}{*}{$0.14 \pm 0.01$} & \multirow[t]{3}{*}{$0.13 \pm 0.01$} & $0.62 \pm 0.08$ & $0.68 \pm 0.11$ & $1.10 \pm 0.13$ \\
\hline & & & & $z$ ratio $=-3.43$ & $z$ ratio $=-2.35$ & $z$ ratio $=0.79$ \\
\hline & & & & $p=0.0018^{\star}$ & $p=0.0481^{*}$ & $p=0.7069$ \\
\hline
\end{tabular}

Odds ratios indicate the odds of detecting that call type in the first intensity level listed compared with the second intensity level listed. *Indicates statistical significance at the $p<0.05$ level; ** indicates statistical significance at the $p<0.001$ level. 
further evidence that they are an intragroup signal aimed at other males (Dunlop and Noad, 2016). Most of the song unit social calls used in the current study were low-frequency, pulsive sounds (Figure 2E). Low frequency pulsed sounds are thought to function in conveying information regarding dominance status, primarily to other males, in some terrestrial mammals (e.g., male rock hyraxes, Procavia capensis; Koren and Geffen, 2009; Demartsev et al., 2016; Weissman et al., 2019) and birds (e.g., male barn swallows, Hirundo rustica (Galeotti et al., 1997). These sounds could contain similar information in whales during humpback whale competitive behavior. However, as low frequency, pulsive song units are also produced while singing, they may also be used to convey the same information (e.g., RHP) but in a different context, supporting the theory that song may serve multiple functions (Herman, 2017; Murray et al., 2018).

Unfortunately, in the present study, the continuous background song precluded automated measurement of any acoustic features of the calls, or any quantitative classification of call types. Using data from the same population reduced the likelihood that a discrete call type was present in the current dataset that was not detected by the previous FKM analysis. However, it is possible that some discrete call types were missed here. Future studies should therefore attempt to perform a quantitative FKM analysis on data directly from competitive groups to identify potential call types that, although not detected in previous studies, are relatively discrete. Using data from other breeding grounds where population sizes are smaller (e.g., Tonga or New Caledonia) may help as there is likely less background chorusing from singing males (Allen, pers. comm.) due to lower numbers on these breeding grounds (Constantine et al., 2012). In the current study, we were also limited to making assumptions about the behavior of the animals based on surface observations. This might not be an accurate representation of their underwater behavior, especially as humpbacks in competitive groups are known to use the entire water column (Herman et al., 2007). However, we carefully determined intensity levels that were discrete and mutually exclusive, providing what is likely a conservative view of the variety of intensity levels observed in competitive groups. Incorporating underwater video will help to validate the correlation between surface and underwater behavior, as well as their relationship with calling behavior.

Overall, we have provided evidence that humpback whales follow similar trends to terrestrial species that engage heavily in male competition during the breeding season. As theories regarding male-male competition predict, humpback whale competitive groups progressed from low intensity displays to higher intensity contests, but with escalated contests being relatively uncommon. Further, we have shown that humpback whales use acoustic signals in concordance with visual displays and threats during this progression. Calls within humpback whale groups classified as low and moderate intensity likely function to convey more fixed information such as body size, while calls in the higher intensity levels likely function to convey flexible information on motivation and arousal. Future research can build from this to compare baleen whale species with drastically different mating strategies, social systems, and vocal repertoires in order to shed light on the link between high communicative complexity and sociality in baleen whales.

\section{DATA AVAILABILITY STATEMENT}

The raw data supporting the conclusions of this article will be made available by the authors, without undue reservation.

\section{ETHICS STATEMENT}

The animal study was reviewed and approved by The University of Queensland Office of Research Ethics.

\section{AUTHOR CONTRIBUTIONS}

DC, MN, RD, and DP conceived the study and assisted with data collection, and edited the final manuscript. DC and DP were responsible for obtaining funding for field data collection. DC oversaw data collection, processed and analyzed all data, interpreted the results, and prepared the final manuscript. All authors contributed to the article and approved the submitted version.

\section{FUNDING}

Great Barrier Reef fieldwork (2017-2019) was funded by the Holsworth Wildlife Research Endowment and the Ecological Society of Australia (\#2017001004), as well as substantial inkind support from Blue Planet Marine, the Cetacean Ecology and Acoustic Laboratory Group, and the University of Queensland. Additional support was provided to the primary author from an American Australian Association Scholarship and a University of Queensland International Scholarship.

\section{ACKNOWLEDGMENTS}

We would like to thank the many people involved in the Great Barrier Reef Whale and Dolphin Research Programme, especially the numerous volunteers, $K$. Indeck for creating the map in Figure 1, J. Allen for her helpful comments on drafts, the three reviewers for their constructive feedback during review, and the Moreton Bay Research Station for hosting the Cetacean Ecology and Acoustics Laboratories Group. Finally, we wish to acknowledge the Quandamooka people, the traditional owners of the land on which the Moreton Bay Research Station was built, and the Ngaro, the traditional owners of the sea country where field work was conducted.

\section{SUPPLEMENTARY MATERIAL}

The Supplementary Material for this article can be found online at: https://www.frontiersin.org/articles/10.3389/fmars.2021. 665186/full\#supplementary-material 


\section{REFERENCES}

Allen, J. A., Garland, E. C., Dunlop, R. A., and Noad, M. J. (2019). Network analysis reveals underlying syntactic features in a vocally learnt mammalian display, humpback whale song. Proc. R. Soc. B 286:20192014. doi: 10.1098/rspb.2019. 2014

Allen, M. L., and Krofel, M. (2017). "Resource holding potential," in Encyclopedia of Animal Cognition and Behavior, eds J. Vonk and T. K. Shackleford (New York, NY: Springer), 1-3. . doi: 10.1007/978-3-319-47829-6_444-1

Altmann, J. (1974). Observational study of behavior: sampling methods. Behaviour 49, 227-266. doi: 10.1163/156853974X00534

August, P. V., and Anderson, J. G. (1987). Mammal sounds and motivationstructural rules: a test of the hypothesis. J. Mammal 68, 1-9. doi: 10.2307/ 1381039

Baker, C. S., and Herman, L. M. (1984). Aggressive behavior between humpback whales (Megaptera novaeangliae) wintering in Hawaiian waters. Can. J. Zool. 62, 1922-1937. doi: 10.1139/z84-282

Bates, D., Mächler, M., Bolker, B., and Walker, S. (2015). Fitting linear mixed-effects models using lme4. J. Statist. Software 67, 1-48. doi: 10.18637/jss.v067.i01

Berta, A., and Sumich, J. L. (1999). "Mating, breeding, and social organization," in Marine Mammals: Evolutionary Biology, 1st Edn, (San Diego, CA: Academic Press), 335-359.

Bezdek, J. C. (1981). “Objective function clustering," in Pattern Recognition with Fuzzy Objective Function Algorithms, (Boston, MA: Springer), 43-93. doi: 10. 1007/978-1-4757-0450-1_3

Boness, D., Clapham, P. J., and Mesnick, S. L. (2002). "Life history and reproductive strategies," in Marine Mammal Biology: an Evolutionary Approach, ed. R. Hoelzel (Hoboken, NJ: Blackwell Science Ltd).

Bradbury, J., and Vehrencamp, S. (2011). Principles of Animal Communication. Sunderland, MA: Sinauer Associates.

Briefer, E. F. (2012). Vocal expression of emotions in mammals: mechanisms of production and evidence. J. Zool. 288, 1-20. doi: 10.1111/j.1469-7998.2012. 00920.x

Briefer, E. F. (2018). Vocal contagion of emotions in non-human animals. Proc. $R$. Soc. B: Biol. Sci. 285:20172783. doi: 10.1098/rspb.2017.2783

Brooks, M. E., Kristensen, K., van Benthem, K. J., Magnusson, A., Berg, C. W., Nielsen, A., et al. (2017b). Modeling zero-inflated count data with glmmTMB. BioRxiv [preprint] doi: 10.1101/132753

Brooks, M. E., Kristensen, K., Van Benthem, K. J., Magnusson, A., Berg, C. W., Nielsen, A., et al. (2017a). glmmTMB balances speed and flexibility among packages for zero-inflated generalized linear mixed modeling. $R$ J. 9, 378-400. doi: 10.32614/RJ-2017-066

Brown, M., and Corkeron, P. (1995). Pod characteristics of migrating humpback whales (Megaptera novaeangliae) off the east Australian coast. Behaviour 132, 163-179. doi: 10.1163/156853995X00676

Brownell, R., and Ralls, K. (1986). Potential for sperm competition in baleen whales. Rep. Int. Whaling Comm. 8, 97-112.

Burmeister, S. S., Ophir, A. G., Ryan, M. J., and Wilczynski, W. (2002). Information transfer during cricket frog contests. Anim. Behav. 64, 715-725. doi: 10.1006/ anbe.2002.4012

Burns, D., Brooks, L., Harrison, P., Franklin, T., Franklin, W., Paton, D., et al. (2014). Migratory movements of individual humpback whales photographed off the eastern coast of Australia. Mar. Mamm. Sci. 30, 562-578. doi: 10.1111/ mms. 12057

Campagna, C. (2009). "Aggressive behavior, intraspecific," in Encyclopedia of Marine Mammals, eds W. F. Perrin, B. Wursig, and J. G. M. Thewissen (Amsterdam: Elsevier). doi: 10.1016/B978-0-12-373553-9.00005-5

Center for Conservation Bioacoustics [CCB] (2014). Raven Pro: Interactive Sound Analysis Software (Version 1.5). Ithaca, NY: The Cornell Lab of Ornithology.

Charlton, B. D., and Reby, D. (2011). Context-related acoustic variation in male fallow deer (Dama dama) groans. PLoS One 6:e21066. doi: 10.1371/journal. pone.0021066

Clapham, P. J. (1993). Social organization of humpback whales on a North Atlantic feeding ground. Symp. Zool. Soc. Lond. 65, 131-145.

Clapham, P. J. (1996). The social and reproductive biology of humpback whales: an ecological perspective. Mammal Rev. 26, 27-49. doi: 10.1111/j.1365-2907.1996. tb00145.x
Clapham, P. J., Mattila, D. K., and Palsbøll, P. J. (1993). High-latitude-area composition of humpback whale competitive groups in Samana Bay: further evidence for panmixis in the North Atlantic population. Can. J. Zool. 71, 1065-1066. doi: 10.1139/z93-142

Clapham, P. J., Palsbøll, P. J., Mattila, D. K., and Vasquez, O. (1992). Composition and dynamics of humpback whale competitive groups in the West Indies. Behaviour. 122, 182-194. doi: 10.1163/156853992X00507

Clark, C. W. (1983). "Acoustic communication and behavior of the southern right whale," in Communication and Behavior of Whales, ed. R. S. Payne (Boulder, CO: Westview Press), 163-198.

Clark, C. W. (1990). “Acoustic behaviour of mysticete whales," in Sensory Abilities of Cetaceans, eds J. A. Thomas and R. A. Kastelein (Boston, MA: Springer), 571-583. doi: 10.1007/978-1-4899-0858-2_40

Clutton-Brock, T. H., and Albon, S. D. (1979). The roaring of red deer and the evolution of honest advertisement. Behaviour 69, 145-170. doi: 10.1163/ 156853979X00449

Constantine, R., Jackson, J. A., Steel, D., Baker, C. S., Brooks, L., Burns, D., et al. (2012). Abundance of humpback whales in Oceania using photo-identification and microsatellite genotyping. Mar. Ecol. Prog. Ser. 453, 249-261. doi: 10.3354/ meps09613

Cusano, D. (2021). Flexible Information in the Social Sounds of Humpback Whales. Ph.D. thesis, Queensland, QLD: University of Queensland. doi: 10.1121/10. 0005111

Cusano, D. A., Noad, M. J., and Dunlop, R. A. (2021). Fuzzy clustering as a tool to differentiate between discrete and graded call types. JASA Exp. Lett. 1:061201. doi: 10.1080/09524622.2020.1858450

Cusano, D. A., Indeck, K. L., Noad, M. J., and Dunlop, R. A. (2020). Humpback whale (Megaptera novaeangliae) social call production reflects both motivational state and arousal. Bioacoustics. 1-24. doi: 10.1080/09524622.2020. 1858450

Darling, J. D. (2001). Characterization of Behavior of Humpback Whales in Hawaiian Waters. Honolulu, HI: Hawaiian Islands Humpback Whale National Marine Sanctuary.

Darling, J. D., and Bérubé, M. (2001). Interactions of singing humpback whales with other males. Mar. Mamm. Sci. 17, 570-584. doi: 10.1111/j.1748-7692.2001. tb01005.x

Demartsev, V., Bar Ziv, E., Shani, U., Goll, Y., Koren, L., and Geffen, E. (2016). Harsh vocal elements affect counter-singing dynamics in male rock hyrax. Behav. Ecol. 27, 1397-1404. doi: 10.1093/beheco/arw063

Dunlop, R. A. (2018b). The communication space of humpback whale social sounds in wind-dominated noise. J. Acoust. Soc. Am. 144, 540-551. doi: 10. $1121 / 1.5047744$

Dunlop, R. (2018a). "The communication space of humpback whale social sounds in vessel noise," in Proceedings of the Meetings on Acoustics 176ASA, (Illinois, ILL: Acoustical Society of America). doi: 10.1121/2.0000935

Dunlop, R. A., Cato, D. H., and Noad, M. J. (2008). Non-song acoustic communication in migrating humpback whales (Megaptera novaeangliae). Mar. Mamm Sci. 24, 613-629. doi: 10.1111/j.1748-7692.2008.00208.x

Dunlop, R. A., Cato, D. H., Noad, M. J., and Stokes, D. M. (2013). Source levels of social sounds in migrating humpback whales (Megaptera novaeangliae). J. Acoust. Soc. Am. 134, 706-714. doi: 10.1121/1.4807828

Dunlop, R. A., and Noad, M. J. (2016). The "risky" business of singing: tactical use of song during joining by male humpback whales. Behav. Ecol. Sociobiol. 70, 2149-2160. doi: 10.1007/s00265-016-2218-2218

Dunlop, R. A., Noad, M. J., Cato, D. H., and Stokes, D. (2007). The social vocalization repertoire of east Australian migrating humpback whales (Megaptera novaeangliae). J. Acoust. Soc. Am. 122, 2893-2905. doi: 10.1121/1. 2783115

Dunlop, R. A., Noad, M. J., McCauley, R. D., Kniest, E., Paton, D., and Cato, D. H. (2015). The behavioural response of humpback whales (Megaptera novaeangliae) to a 20 cubic inch air gun. Aquat. Mamm. 41, 412-433. doi: 10.1578/AM.41.4.2015.412

Dunlop, R. A., Noad, M. J., McCauley, R. D., Kniest, E., Slade, R., Paton, D., et al. (2016). Response of humpback whales (Megaptera novaeangliae) to rampup of a small experimental air gun array. Mar. Pollut. Bull. 103, 72-83. doi: 10.1016/j.marpolbul.2015.12.044 
D’Vincent, C. G., Nilson, R. M., and Hanna, R. E. (1985). Vocalization and coordinated feeding behavior of the humpback whale in southeastern Alaska. Sci. Rep. Whales Res. Institute 36, 41-47.

Edds-Walton, P. L. (1997). Acoustic communication signals of mysticete whales. Bioacoustics 8, 47-60. doi: 10.1080/09524622.1997.9753353

Enquist, M. (1985). Communication during aggressive interactions with particular reference to variation in choice of behaviour. Anim. Behav. 33, 1152-1161. doi: 10.1016/S0003-3472(85)80175-5

Félix, F., and Novillo, J. (2015). Structure and dynamics of humpback whales competitive groups in Ecuador. Anim. Behav. Cogn. 2, 56-70. doi: 10.12966/ abc.02.05.2015

Ferraro, M. B., and Giordani, P. (2015). A toolbox for fuzzy clustering using the R programming language. Fuzzy Sets Systems 279, 1-16. doi: 10.1016/j.fss.2015. 05.001

Fischer, J., Wadewitz, P., and Hammerschmidt, K. (2017). Structural variability and communicative complexity in acoustic communication. Anim. Behav. 134, 229-237. doi: 10.1016/j.anbehav.2016.06.012

Fournet, M. E. H., Szabo, A., and Mellinger, D. K. (2015). Repertoire and classification of non-song calls in Southeast Alaskan humpback whales (Megaptera novaeangliae). J. Acoust. Soc. Am. 137, 1-10. doi: 10.1121/1. 4904504

Galeotti, P., Saino, N., Sacchi, R., and Møller, A. P. (1997). Song correlates with social context, testosterone and body condition in male barn swallows. Anim. Behav. 53, 687-700. doi: 10.1006/anbe.1996.0304

Garland, E. C., Goldizen, A. W., Lilley, M. S., Rekdahl, M. L., Garrigue, C., Constantine, R., et al. (2015). Population structure of humpback whales in the western and central South Pacific Ocean as determined by vocal exchange among populations. Conserv. Biol. 29, 1198-1207. doi: $10.1111 /$ cobi.12492

Gower, J. C. (1971). A general coefficient of similarity and some of its properties. Biometrics 27, 857-871. doi: 10.2307/2528823

Green, S., and Marler, P. (1979). "The analysis of animal communication," in Social Behavior and Communication, eds P. Marler and J. G. Vandenbergh (Boston, MA: Springer), 73-158. doi: 10.1007/978-1-46159116-0_3

Hafner, G. W., Hamilton, C. L., Steiner, W. W., Thompson, T. J., and Winn, H. E. (1979). Signature information in the song of the humpback whale. J. Acoust. Soc. Am. 66, 1-6. doi: 10.1121/1.383072

Hardy, I. C., and Briffa, M. (2013). Animal Contests. Cambridge: Cambridge University Press. doi: 10.1017/CBO9781139051248

Hauser, M. D. (1996). The Evolution of Communication. Cambridge, MA: MIT press.

Helweg, D. A., and Herman, L. M. (1994). Diurnal patterns of behaviour and group membership of humpback whales (Megaptera novaeangliae) wintering in Hawaiian waters. Ethology 98, 298-311. doi: 10.1111/j.1439-0310.1994. tb01078.x

Herman, E. Y., Herman, L. M., Pack, A. A., Marshall, G., Shepard, M. C., and Bakhtiari, M. (2007). When whales collide: crittercam offers insight into the competitive behavior of humpback whales on their Hawaiian wintering grounds. Mar. Technol. Soc. J. 41, 35-43. doi: 10.4031/ 002533207787441971

Herman, L. M. (2017). The multiple functions of male song within the humpback whale (Megaptera novaeangliae) mating system: review, evaluation, and synthesis. Biol. Rev. 92, 1795-1818. doi: 10.1111/brv. 12309

Hof, D., and Podos, J. (2013). Escalation of aggressive vocal signals: a sequential playback study. Proc. R. Soc. B: Biol. Sci. 280:20131553. doi: 10.1098/rspb.2013. 1553

Hofmann, H. A., and Schildberger, K. (2001). Assessment of strength and willingness to fight during aggressive encounters in crickets. Anim. Behav. 62, 337-348. doi: 10.1006/anbe.2001.1746

Indeck, K. L., Girola, E., Torterotot, M., Noad, M. J., and Dunlop, R. A. (2021). Adult female-calf acoustic communication signals in migrating east Australian humpback whales. Bioacoustics 30, 341-365. doi: 10.1080/09524622.2020. 1742204

Insley, S., Phillips, A. V., and Charrier, I. (2003). A review of social recognition in pinnipeds. Aquat. Mamm. 29, 181-201. doi: 10.1578/016754203101024149
Jurasz, C. M., and Jurasz, V. P. (1979). Feeding modes of the humpback whale, Megaptera novaeangliae, in Southeast Alaska. Sci. Rep. Whales Res. Institute 31, 69-83.

Katona, S., and Whitehead, H. (1981). Identifying humpback whales using their natural markings. Polar Rec. 20, 439-444. doi: 10.1017/S003224740000365X

Kaufman, L., and Rousseeuw, P. J. (2009). Finding Groups in Data: an Introduction to Cluster Analysis. Hoboken, NJ: John Wiley \& Sons.

Koren, L., and Geffen, E. (2009). Complex call in male rock hyrax (Procavia capensis): a multi-information distributing channel. Behav. Ecol. Sociobiol. 63, 581-590. doi: 10.1007/s00265-008-0693-2

Kotiaho, J. S., Alatalo, R. V., Mappes, J., and Parri, S. (1999). Honesty of agonistic signalling and effects of size and motivation asymmetry in contests. Acta Ethol. 2, 13-21. doi: 10.1007/PL00012227

Kraus, S. D., and Hatch, J. J. (2001). Mating strategies in the North Atlantic right whale (Eubalaena glacialis). J. Cetacean Res. Manag. Special Issue 2, 237-244.

Lenth, R. (2021). Emmeans: Estimated Marginal Means, Aka Least-Squares Means. $R$ Package Version 1.6.2-1. Available online at: https://cran.r-project.org/ package =emmeans (accessed September 5, 2021).

Lingle, S., Wyman, M. T., Kotrba, R., Teichroeb, L. J., and Romanow, C. A. (2012). What makes a cry a cry? a review of infant distress vocalizations. Curr. Zool. 58, 698-726. doi: 10.1093/czoolo/58.5.698

Maechler, M., Rousseeuw, P., Struyf, A., Hubert, M., and Hornik, K. (2019). Cluster: Cluster Analysis Basics and Extensions. 2.1.0. Available online at: https://cran.rproject.org/package $=$ cluster (accessed September 5, 2021).

Manser, M. B. (2010). "The generation of functionally referential and motivational vocal signals in mammals," in Handbook of Behavioral Neuroscience, ed. S. M. Brudzynski (London: Academic Press), 477-486. doi: 10.1016/B978-0-12374593-4.00043-7

Marler, P. (1961). The logical analysis of animal communication. J. Theor. Biol. 1, 295-317. doi: 10.1016/0022-5193(61)90032-7

Marler, P. (1975). On the origin of speech from animal sounds. Role Speech Lang. $11: 37$.

Marler, P. (1976). "Social organization, communication and graded signals: the chimpanzee and the gorilla," in Growing Points Ethology, eds P. P. G. Bateson and R. A. Hinde (Cambridge: Cambridge University Press).

Marler, P. (1977). "The structure of animal communication sounds," in Recognition of Complex Acoustic Signals, eds T. Bullock and E. Evans (Berlin: Dahlem Konferenzen), 17-35.

Marler, P., Evans, C. S., and Hauser, M. D. (1992). “Animal signals: motivational, referential, or both?” in Nonverbal Vocal Communication: Comparative and Developmental Approaches, eds H. Papousek, U. Jurgens, and M. Papousek (Cambridge: Cambridge University Press), 66-86.

Mattila, D. K., Clapham, P. J., Katona, S. K., and Stone, G. S. (1989). Population composition of humpback whales, Megaptera novaeangliae, on Silver Bank, 1984. Can. J. Zool. 67, 281-285. doi: 10.1139/z89-041

May-Collado, L. J., Agnarsson, I., and Wartzok, D. (2007). Reexamining the relationship between body size and tonal signals frequency in whales: a comparative approach using a novel phylogeny. Mar. Mamm. Sci. 23, 524-552. doi: $10.1111 /$ j.1748-7692.2007.02250.x

Maynard-Smith, J. (1974). The theory of games and the evolution of animal conflicts. J. Theor. Biol. 47, 209-221. doi: 10.1016/0022-5193(74)90110-6

Maynard-Smith, J., and Harper, D. (2003). Animal Signals. Oxford: Oxford University Press.

McElligott, A. G., Gammell, M. P., Harty, H. C., Paini, D. R., Murphy, D. T., Walsh, J. T., et al. (2001). Sexual size dimorphism in fallow deer (Dama dama): do larger, heavier males gain greater mating success? Behav. Ecol. Sociobiol. 49, 266-272. doi: 10.1007/s002650000293

McElligott, A. G., and Hayden, T. J. (1999). Context-related vocalization rates of fallow bucks. Dama dama. Anim. Behav. 58, 1095-1104. doi: 10.1006/anbe. 1999.1237

Mesnick, S. L., and Ralls, K. (2009). "Mating systems," in Encyclopedia of Marine Mammals, eds W. F. Perrin, B. Wursig, and J. G. M. Thewissen (Amsterdam: Academic Press), 712-719. doi: 10.1016/B978-0-12-373553-9. 00165-6

Morton, E. S. (1977). On the occurrence and significance of motivation-structural rules in some bird and mammal sounds. Am. Nat. 111, 855-869. doi: 10.1086/ 283219 
Morton, E. S. (1982). "Grading, discreteness, redundancy, and motivationstructural rules," in Acoustic Communication in Birds, eds D. E. Kroodsma and M. H. Miller (New York, NY: Academic Press), 183-212. doi: 10.1016/B978-008-092416-8.50015-2

Murray, A., Dunlop, R. A., Noad, M. J., and Goldizen, A. W. (2018). Stereotypic and complex phrase types provide structural evidence for a multi-message display in humpback whales (Megaptera novaeangliae). J. Acoust. Soc. Am. 143, 980-994. doi: $10.1121 / 1.5023680$

Noad, M. J., Kniest, E., and Dunlop, R. A. (2019). Boom to bust? Implications for the continued rapid growth of the eastern Australian humpback whale population despite recovery. Popul. Ecol. 61, 198-209. doi: 10.1002/1438-390X. 1014

Owings, D. H., and Morton, E. S. (1998). Animal Vocal Communication: a New Approach. Cambridge: Cambridge University Press. doi: 10.1017/ CBO9781139167901

Pack, A. A., Salden, D. R., Ferrari, M. J., Glockner-Ferrari, D. A., Herman, L. M., Stubbs, H. A., et al. (1998). Male humpback whale dies in competitive group. Mar. Mamm. Sci. 14, 861-873. doi: 10.1111/j.1748-7692.1998.tb00771.x

Parker, G. A. (1974). Assessment strategy and the evolution of fighting behaviour. J. Theor. Biol. 47, 223-243. doi: 10.1016/0022-5193(74)90111-8

Parks, S. E. (2003). Response of north Atlantic right whales (Eubalaena glacialis) to playback of calls recorded from surface active groups in both the north and South Atlantic. Mar. Mamm. Sci. 19, 563-580. doi: 10.1111/j.1748-7692.2003. tb01321.x

Parks, S. E., Brown, M. W., Conger, L. A., Hamilton, P. K., Knowlton, A. R., Kraus, S. D., et al. (2007). Occurrence, composition, and potential functions of North Atlantic right whale (Eubalaena glacialis) surface active groups. Mar. Mamm. Sci. 23, 868-887. doi: 10.1111/j.1748-7692.2007.00154.x

Parks, S. E., Cusano, D. A., Stimpert, A. K., Weinrich, M. T., Friedlaender, A. S., and Wiley, D. N. (2014). Evidence for acoustic communication among bottom foraging humpback whales. Sci. Rep. 4:7508. doi: 10.1038/srep07508

Parks, S. E., and Tyack, P. L. (2005). Sound production by North Atlantic right whales (Eubalaena glacialis) in surface active groups. J. Acoust. Soc. Am. 117, 3297-3306. doi: 10.1121/1.1882946

Payne, K., Tyack, P. L., and Payne, R. (1983). "Progressive changes in the songs of humpback whales (Megaptera novaeangliae): a detailed analysis of two seasons in Hawaii," in Communication and Behavior of Whales, ed. R. Payne (Boulder, CO: Westview Press).

Payne, K. B., and Payne, R. S. (1985). Large scale changes over 19 years in songs of humpback whales in Bermuda. Zeitschrift für Tierpsychologie 68, 89-114. doi: 10.1111/j.1439-0310.1985.tb00118.x

Payne, R., and Dorsey, E. (1983). "Sexual dimorphism and aggressive use of callosities in right whales (Eubalaena australis)," in Communication and Behavior of Whales, ed. R. S. Payne (Boulder, CO: Westview Press), 295-329.

Payne, R. S., and McVay, S. (1971). Songs of humpback whales. Science 173, 585-597. doi: 10.1126/science.173.3997.585

R Core Team (2020). R: A Language and Environment for Statistical Computing. Vienna: R Foundation for Statistical Computing.

Ramp, C., Hagen, W., Palsbøll, P., Bérubé, M., and Sears, R. (2010). Age-related multi-year associations in female humpback whales (Megaptera novaeangliae). Behav. Ecol. Sociobiol. 64, 1563-1576. doi: 10.1007/s00265-010-0970-978

Reby, D., and McComb, K. (2003b). Vocal communication and reproduction in deer. Adv. Study Behav. 33, 231-264. doi: 10.1016/S0065-3454(03)33005-0

Reby, D., and McComb, K. (2003a). Anatomical constraints generate honesty: acoustic cues to age and weight in the roars of red deer stags. Anim. Behav. 65, 519-530. doi: 10.1006/anbe.2003.2078

Reby, D., McComb, K., Cargnelutti, B., Darwin, C., Fitch, W. T., and CluttonBrock, T. (2005). Red deer stags use formants as assessment cues during intrasexual agonistic interactions. Proc. R. Soc. B: Biol. Sci. 272, 941-947. doi: 10.1098/rspb.2004.2954

Rekdahl, M., Tisch, C., Cerchio, S., and Rosenbaum, H. (2017). Common nonsong social calls of humpback whales (Megaptera novaeangliae) recorded off northern Angola, southern Africa. Mar. Mamm. Sci. 33, 365-375. doi: 10. 1111/mms. 12355

Rekdahl, M. L., Dunlop, R. A., Noad, M. J., and Goldizen, A. W. (2013). Temporal stability and change in the social call repertoire of migrating humpback whales. J. Acoust. Soc. Am. 133, 1785-1795. doi: 10.1121/1.4789941
Rugh, D. J., and Shelden, K. E. (2009). "Bowhead whale: Balaena mysticetus," in Encyclopedia of Marine Mammals, eds W. F. Perrin, B. Wursig, and J. G. M. Thewissen (Amsterdam: Academic Press), 131-133. doi: 10.1016/B978-0-12373553-9.00036-5

Silber, G. K. (1986). The relationship of social vocalizations to surface behavior and aggression in the Hawaiian humpback whale (Megaptera novaeangliae). Can. J. Zool. 64, 2075-2080. doi: 10.1139/z86-316

Smith, J. M., and Price, G. R. (1973). The logic of animal conflict. Nature 246, 15-18. doi: $10.1038 / 246015 \mathrm{a} 0$

Smith, J. N., Grantham, H. S., Gales, N., Double, M. C., Noad, M. J., and Paton, D. (2012). Identification of humpback whale breeding and calving habitat in the Great Barrier Reef. Mar. Ecol. Prog. Ser. 447, 259-272. doi: 10.3354/meps09462

Smith, W. (1977). The Behavior of Communicating: An Ethological Approach. Cambridge: Harvard University Press. doi: 10.4159/9780674043794

Spitz, S. S., Herman, L. M., Pack, A. A., and Deakos, M. H. (2002). The relation of body size of male humpback whales to their social roles on the Hawaiian winter grounds. Can. J. Zool. 80, 1938-1947. doi: 10.1139/z02-177

Stimpert, A. K., Au, W. W., Wiley, D. N., and Mattila, D. (2008). Contextual sound production by tagged humpback whales (Megaptera novaeangliae) on a feeding and breeding ground. J. Acoust. Soc. Am. 124, 2484-2484. doi: $10.1121 / 1.4782751$

Stimpert, A. K., Au, W. W. L., Parks, S. E., Hurst, T., and Wiley, D. N. (2011). Common humpback whale (Megaptera novaeangliae) sound types for passive acoustic monitoring. J. Acoust. Soc. Am. 129, 476-482. doi: 10.1121/1.3504708

Stimpert, A. K., Wiley, D. N., Au, W. W. L., Johnson, M. P., and Arsenault, R. (2007). 'Megapclicks': acoustic click trains and buzzes produced during nighttime foraging of humpback whales (Megaptera novaeangliae). Biol. Lett. 3, 467-470. doi: 10.1098/rsbl.2007.0281

Thompson, P. O., Cummings, W. C., and Ha, S. J. (1986). Sounds, source levels, and associated behavior of humpback whales, Southeast Alaska. J. Acoust. Soc. Am. 80, 735-740. doi: 10.1121/1.393947

Tyack, P. L. (1981). Interactions between singing Hawaiian humpback whales and conspecifics nearby. Behav. Ecol. Sociobiol. 8, 105-116. doi: 10.1007/ BF00300822

Tyack, P. L., and Whitehead, H. (1983). Male competition in large groups of wintering humpback whales. Behaviour 83, 132-154. doi: 10.1163/ $156853982 X 00067$

Vannoni, E., and McElligott, A. G. (2008). Low frequency groans indicate larger and more dominant fallow deer (Dama dama) males. PLoS One 3:e3113. doi: 10.1371/journal.pone.0003113

Ver Hoef, J. M., and Boveng, P. L. (2007). Quasi-Poisson vs. negative binomial regression: how should we model overdispersed count data? Ecology 88, 27662772. doi: 10.1890/07-0043.1

Wadewitz, P., Hammerschmidt, K., Battaglia, D., Witt, A., Wolf, F., and Fischer, J. (2015). Characterizing vocal repertoires-Hard vs. soft classification approaches. PLoS One 10:e0125785. doi: 10.1371/journal.pone.0125785

Wagner, W. E. Jr. (1989). Graded aggressive signals in Blanchard's cricket frog: vocal responses to opponent proximity and size. Anim. Behav. 38, 1025-1038. doi: 10.1016/S0003-3472(89)80141-1

Weinrich, M. T. (1991). Stable social associations among humpback whales (Megaptera novaeangliae) in the southern Gulf of Maine. Can. J. Zool. 69, 3012-3019. doi: 10.1139/z91-425

Weissman, Y. A., Demartsev, V., Ilany, A., Barocas, A., Bar-Ziv, E., Shnitzer, I., et al. (2019). Acoustic stability in hyrax snorts: vocal tightrope-walkers or wrathful verbal assailants? Behav. Ecol. 30, 223-230. doi: 10.1093/beheco/ ary141

Winn, H. E., Beamish, P., and Perkins, P. J. (1979). Sounds of two entrapped humpback whales (Megaptera novaeangliae) in Newfoundland. Mar. Biol. 55, 151-155. doi: 10.1007/BF00397311

Winn, H. E., and Winn, L. K. (1978). The song of the humpback whale Megaptera novaeangliae in the West Indies. Mar. Biol. 47, 97-114. doi: 10.1007/ BF00395631

Würsig, B., Guerrero, J., and Silber, G. K. (1993). Social and sexual behavior of bowhead whales in fall in the western arctic: a re-examination of seasonal trends. Mar. Mamm. Sci. 9, 103-115. doi: 10.1111/j.1748-7692.1993.tb00434.x

Zahavi, A. (1982). The pattern of vocal signals and the information they convey. Behaviour 80, 1-8. doi: 10.1163/156853982X00409 
Zoidis, A. M., Smultea, M. A., Frankel, A. S., Hopkins, J. L., Day, A., McFarland, A. S., et al. (2008). Vocalizations produced by humpback whale (Megaptera novaeangliae) calves recorded in Hawaii. J. Acoust. Soc. Am. 123, 1737-1746. doi: 10.1121/1.28 36750

Conflict of Interest: DC was employed by the company JASCO Applied Sciences. This affiliation began after the presented research took place.

The remaining authors declare that the research was conducted in the absence of any commercial or financial relationships that could be construed as a potential conflict of interest.
Publisher's Note: All claims expressed in this article are solely those of the authors and do not necessarily represent those of their affiliated organizations, or those of the publisher, the editors and the reviewers. Any product that may be evaluated in this article, or claim that may be made by its manufacturer, is not guaranteed or endorsed by the publisher.

Copyright (c) 2021 Cusano, Paton, Noad and Dunlop. This is an open-access article distributed under the terms of the Creative Commons Attribution License (CC BY). The use, distribution or reproduction in other forums is permitted, provided the original author(s) and the copyright owner(s) are credited and that the original publication in this journal is cited, in accordance with accepted academic practice. No use, distribution or reproduction is permitted which does not comply with these terms. 